\title{
Towards Integrated Powertrain Control for a Mild-Hybrid Urban Vehicle with a Downsized Turbo-Charged CNG Engine
}

\author{
P. Tona, P. Moulin, S. Venturi, R. Tilagone and P. Gautier \\ Institut français du pétrole, IFP, 1-4, avenue de Bois-Préau, 92852 Rueil-Malmaison Cedex - France \\ e-mail: paolino.tona@ifp.fr - philippe.moulin@ifp.fr - stephane.venturi@ifp.fr - richard.tilagone@ifp.fr - pierre.gautier@ifp.fr
}

Résumé - Vers le contrôlé intégré du groupe moto-propulseur pour un véhicule urbain hybride avec un moteur éco-suralimenté au GNV - Pour son abondance et sa capacité à réduire les émissions des gaz à effet de serre (notamment le $\mathrm{CO}_{2}$ ), le gaz naturel pour véhicules (GNV) est considéré comme l'un des carburants alternatifs les plus prometteurs. Le potentiel du GNV, lorsqu'il est utilisé comme carburant d'un moteur éco-suralimenté dédié sur un petit véhicule urbain, a déjà été démontré par un premier prototype réalisé par l'IFP. Pour mieux profiter des qualités du GNV, cette approche peut être ultérieurement développée en exploitant les possibilités offertes par un groupe moto-propulseur hybride, obtenu en rajoutant au moteur thermique GNV une deuxième source de puissance, électrique cette foisci. Dans cette perspective, VEHGAN, un nouveau projet de l'IFP, vise précisément à développer un prototype de véhicule hybride léger au GNV basé sur une Smart équipée du système StARS de Valeo, avec un alterno-démarreur réversible et des super-capacités. Le déroulement de ce projet, encore en cours, a d'ores et déjà soulevé des problématiques contrôle moteur très intéressantes, telles que l'intégration d'une nouvelle source de puissance et la gestion du système de transmission robotisé.

\begin{abstract}
Towards Integrated Powertrain Control for a Mild-Hybrid Urban Vehicle with a Downsized Turbo-Charged CNG Engine - Compressed natural gas (CNG) is considered as one of the most promising alternative fuels for transportation due to its ability to reduce greenhouse gas emissions $\left(\mathrm{CO}_{2}\right.$, in particular) and its abundance. An earlier study from IFP has shown that CNG has a considerable potential when used as a fuel for a dedicated downsized turbo-charged SI engine on a small urban vehicle. To take further advantage of CNG assets, this approach can be profitably extended by adding a small secondary (electrical) power source to the CNG engine, thus hybridizing the powertrain. This is precisely the focus of the new IFP project, VEHGAN, which aims to develop a mild-hybrid CNG prototype vehicle based on a MCC Smart car equipped with a reversible starter-alternator and ultra-capacitors (Valeo Starter Alternator Reversible System, StARS). The unfolding of this project has involved and will involve several interesting and challenging issues from an engine control point of view, such as mastering the automatic manual transmission (AMT) control system and integrating a new power source, with its new functions, into the torque-oriented engine control structure.
\end{abstract}




\section{INTRODUCTION}

Compressed natural gas $(\mathrm{CNG})$ is considered as one of the most promising alternative fuels for transportation due to its abundance and its ability to reduce in urban area both greenhouse gas emissions and pollutant emissions.

As a matter of fact, CNG is not only an environmentally friendly fuel, but also a highly efficient one. As shown by an earlier study conducted by IFP in partnership with Gaz de France and partially funded by ADEME, CNG has a considerable potential when used as fuel for a dedicated downsized turbo-charged SI engine on a small urban vehicle [1].

The results obtained with this first demonstrator vehicle, a MCC Smart with a dedicated $600 \mathrm{cc}$ engine, were very encouraging, with, for instance, $27 \%$ reduction of $\mathrm{CO}_{2}$ emissions on the NEDC cycle, and good driveability. Nonetheless, we found that there still is room for improvements of this concept, both in terms of engine and vehicle performances. More particularly, it turned out that the turbocharger could only partially compensate for high engine speed the reduction of volumetric efficiency, due to natural gas injection, which in turns affects brake mean effective pressure (BMEP) at low speed. A possible solution to recover torque at low speed is to provide electrical assistance to the CNG engine: a small ( $3 \mathrm{~kW})$ motor-alternator would supply the necessary extra-power for peak load conditions and totally compensate the penalty.

This is precisely the focus of VEHGAN, an ongoing IFP project which aims to develop a mild-hybrid CNG prototype vehicle based on another MCC Smart equipped with a reversible starter-alternator and ultra-capacitors (Valeo Starter Alternator Reversible System, StARS). The partners involved are Valeo and Gaz de France with financial support from ADEME.

The potential of this solution cannot be fully exploited without mastering the automatic manual transmission (AMT) control system. We thus replaced the original AMT control system of the production vehicle, implemented through a network of decentralized electronic control units (ECUs), with a powertrain control system integrating engine, motor and transmission control. This solution provides tight control of the power flow through the powertrain and ensures maximum flexibility for the design and fast prototyping of energy management strategies.

This article gives an overview of the work done so far on the integrated powertrain control system for the new Smart demonstrator. We will mostly focus on the AMT part, since the implementation of the starter-alternator part has not been finalized yet.

\section{CONTEXT}

\subsection{The Smart Demonstrator Approach: an Urban Vehicle with a Downsized Turbo-Charged CNG Engine}

\subsubsection{Natural Gas as an Alternative Fuel}

Natural gas has a strong potential as an alternative fuel, due to several interesting features:

- natural gas resources are equivalent to oil in term of energy ready to be exploited, and are homogeneously spread on earth;

- local emissions from natural gas vehicles present low reactivity and toxicity (Fig. 1);

- due to $\mathrm{H} / \mathrm{C}$ molecular ratio close to four, (tank-to-wheel) $\mathrm{CO}_{2}$ emissions at stoichiometric condition are $23 \%$ lower than gasoline;

- several well-to-wheel analysis also agree on natural gas being a promising way to reduce equivalent $\mathrm{CO}_{2}$ emissions (Table 1);

- thanks to its high knocking resistance (RON number higher than 120), engines using natural gas can be designed with higher compression ratio (than conventional gasoline one), and maximum best torque (MBT) advances can be selected with continuous stoichiometric conditions whatever the load and engine speed, leading to substantial reduction of consumption.

However, some drawbacks should also be mentioned:

- high tank capacity and high pressure are needed for gaseous storage, because of its small low heat value;

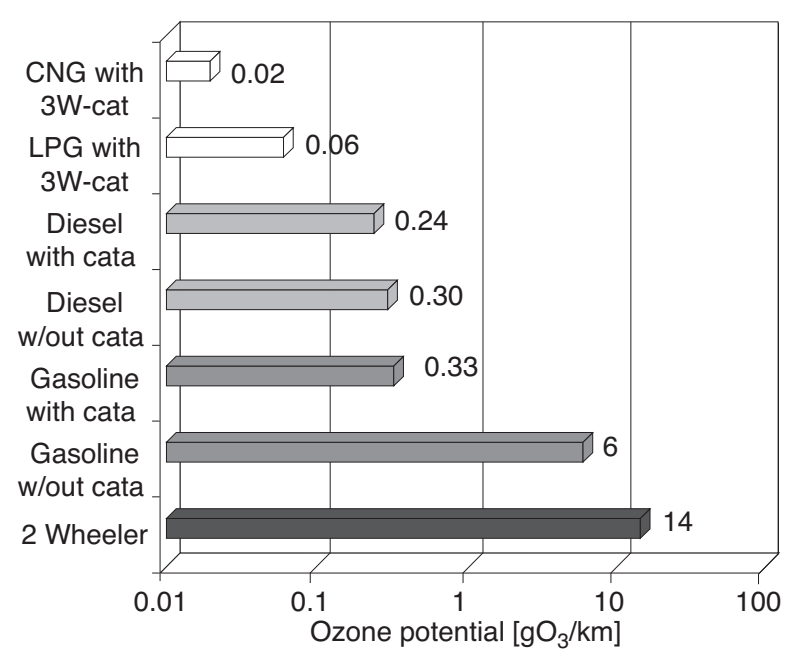

Figure 1

Potential of ozone formation for several vehicles. 
- natural gas characteristics such as air/fuel ratio, low heat value and knock index vary in accordance with its composition, even though the rated engine power for constant air/fuel ratios does not vary much.

TABLE 1

Theoretical $\mathrm{CO}_{2}$ emissions for stoichiometric combustion

\begin{tabular}{l|c|c|c|c|c|c}
\hline & $\mathrm{H} / \mathrm{C}$ & \multicolumn{2}{|c|}{$\begin{array}{c}\mathrm{CO}_{2} \\
(\mathrm{~g} / \mathrm{g} \text { of fuel) }\end{array}$} & $\begin{array}{c}\mathrm{LHV} \\
(\mathrm{kJ} / \mathrm{kg})\end{array}$ & \multicolumn{2}{c}{$\begin{array}{c}\mathrm{CO}_{2} \\
(\mathrm{~g} / \mathrm{kJ}) \times 1000\end{array}$} \\
\hline Natural Gas & $3.7 / 3.9$ & 2.75 & $-13,5 \%$ & 48,444 & 56.8 & $-23,8 \%$ \\
\hline LPG (50/50) & 2.5 & 3.03 & $-4,7 \%$ & 46,055 & 65.8 & $-11,7 \%$ \\
\hline Diesel/Fuel & 1.9 & 3.17 & $-0,3 \%$ & 42,769 & 74.1 & $-0,5 \%$ \\
\hline Gasoline & 1.8 & 3.18 & - & 42,690 & 74.5 & - \\
\hline
\end{tabular}

\subsubsection{Downsizing and Supercharging}

The reduction of engine size is an efficient way to reduce specific consumption by reducing friction losses for engine load controlled by a throttle, and promoting better efficiency conditions (higher loads).

For instance, to drive a mid-range vehicle at constant speed of $70 \mathrm{~km} / \mathrm{h}$, a conventional gasoline port injection engine should approximately develop an output power of $7 \mathrm{~kW}$. This output power represents at $2000 \mathrm{rpm}$ a brake mean effective pressure (BMEP) of 2 bar for a 2-liters displacement engine and twice for a 1-liter displacement engine. Figure 2 shows a representative specific fuel consumption (SFC) map of current conventional gasoline engine. For this

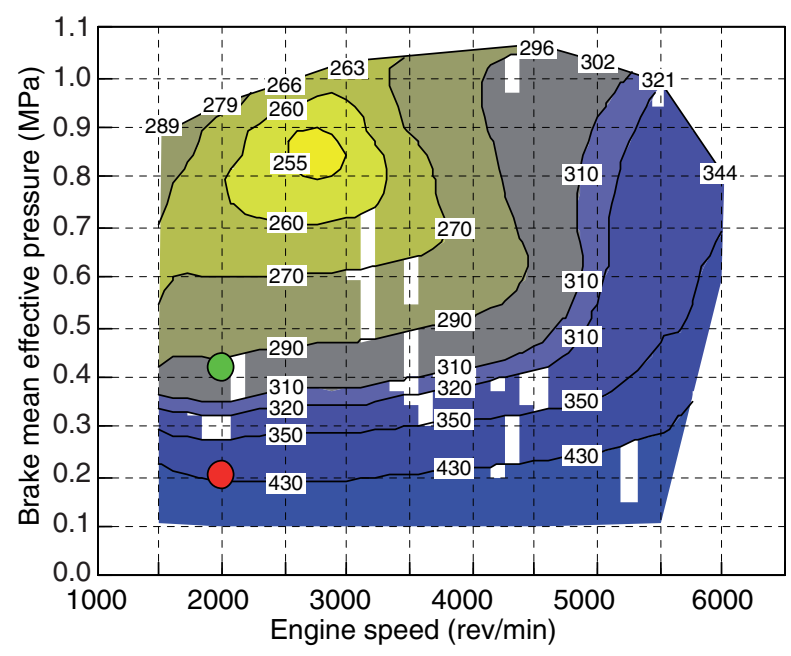

Figure 2

Specific consumption $(\mathrm{g} / \mathrm{kWh})$ for a conventional medium size SI-FPI gasoline engine. simple case, divided swept volume by 2 results in reducing the specific consumption from $400 \mathrm{~g} / \mathrm{kWh}$ to $300 \mathrm{~g} / \mathrm{kWh}$, so $\mathrm{CO}_{2}$ emissions by $25 \%$.

Nevertheless, size reduction must be limited to avoid requirement of too high a BMEP, especially for gasoline applications due to knock sensitivity and pollution. More, reducing swept volume affects performances for naturally aspirated conditions, with more severe penalty for a natural gas engine due to gaseous phase (volumetric efficiency could be affected by over $10 \%$ ).

The performance drop can be partially removed with stoichiometric conditions, more suitable to cope with stringent emissions regulation, using proven three-ways catalyst and with fewer penalties to control transient conditions. Using a supercharger is another efficient way to overcome this drawback.

In case of downsized turbocharged Natural Gas engine, stoichiometric approach leads to higher exhaust temperature helpful both to optimize enthalpy of exhaust gas and to reduce unburned hydrocarbon during cold start-up phase.

\subsubsection{Technical Features of the Production Smart $600 \mathrm{cc}$ Engine}

The Smart vehicle offers characteristics proper to urban vehicles: small dimensions, light weight, low consumption and low emissions.

Designed by SUPREX for MCC, the mechanical features of its 3 cylinder-in-line engine are as follows:

- bore $\times$ stroke: $63.5 \mathrm{~mm} \times 63 \mathrm{~mm}$;

- swept volume: $599 \mathrm{cc}$;

- gasoline compression ratio: 9.5:1.

Output performances announced by MCC are attainable with the GT12 cooled turbocharger produced by Allied Signal Automotive (GARRETT), allowing over-boost conditions. In this case, the intake manifold pressure is regulated to 2 bars instead of 1.8 bars:

- output power: $40 \mathrm{~kW}$ at $5250 \mathrm{rev} / \mathrm{min}$;

- maximum torque: $80 \mathrm{Nm}$ from $2000 \mathrm{rev} / \mathrm{min}$ to 4500 $\mathrm{rev} / \mathrm{min}$;

- maximum over boost torque: $88 \mathrm{Nm}$ from $2000 \mathrm{rev} / \mathrm{min}$ to $4500 \mathrm{rev} / \mathrm{min}$.

The air coming from the compressor is cooled with a specific air/air cooler without any exhaust gas recirculation.

The same camshaft in the cylinder head (with hydraulic valve lift), driven with a chain actuates the two valves on each cylinder. The exhaust manifold includes a turbine house, allowing thermal losses to be reduced, then the maximum of exhaust gas enthalpy to be obtained. Two spark plugs per cylinder stabilize the combustion at delayed spark advance. 


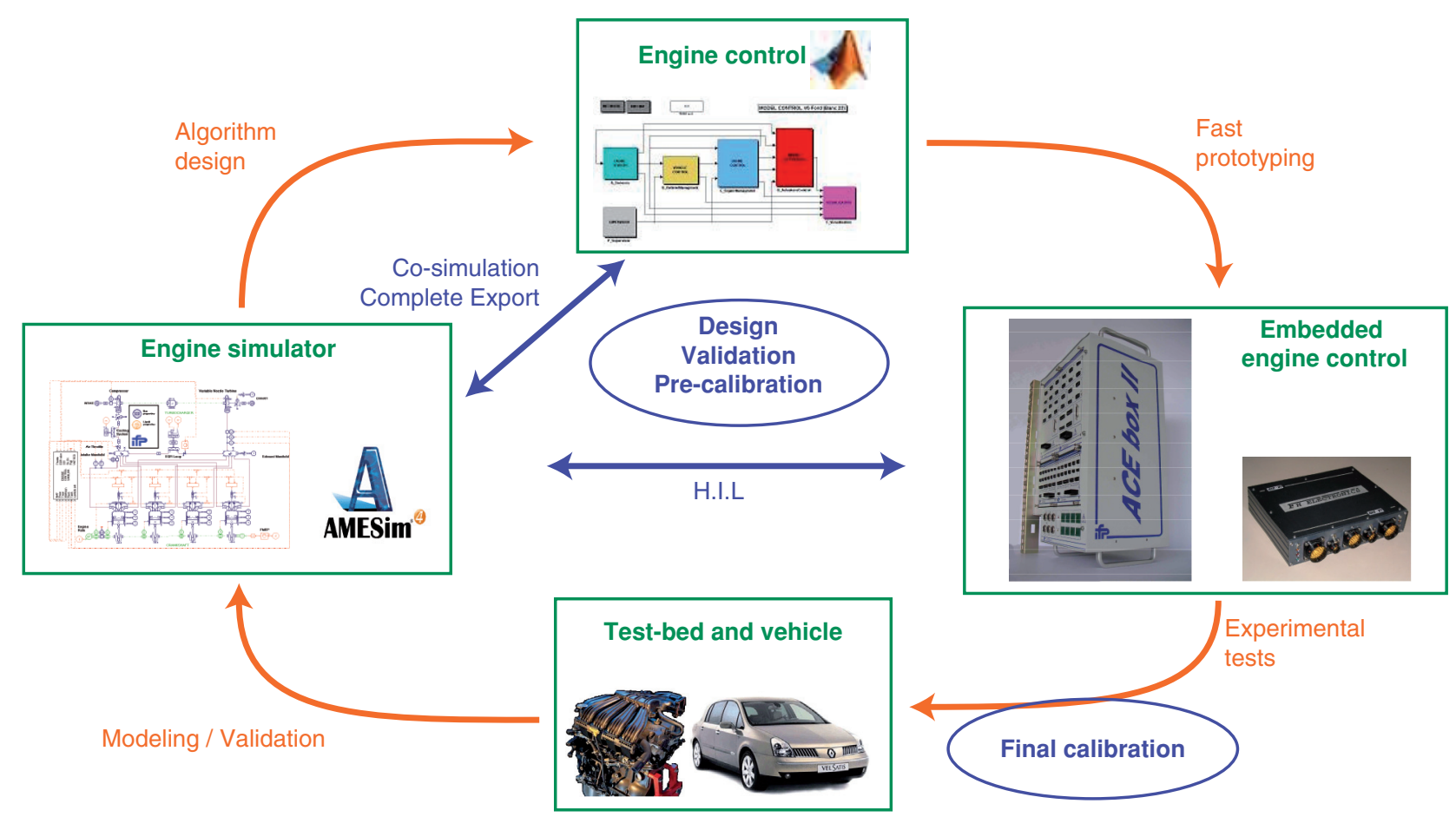

Figure 3

IFP engine control development cycle.

\subsubsection{Adaptation of Engine and Vehicle to CNG}

The initial step of the Smart demonstrator approach has consisted in adapting the production engine and vehicle to the use of CNG fuel.

More particularly, compression ratio of the engine used for the first demonstrator had been increased from 9.5:1 to 12.0:1. Due to higher in-cylinder pressure (best-torque spark advance and higher compression ratio) new strengthened pistons were designed and machined. Connecting rods were modified too. Low-pressure natural gas injectors (less than 4 bar) from Keihin were selected needing lower electrical power and reducing leakage after engine switch-off. Dedicated natural gas rail and injectors were fitted on the intake manifold without any design modification. Three tanks built with composite material were designed and machined by Ullit Company. With a total storage capacity of 35 liters, the driving range for fuel consumption representative of MVEG cycle was approximately $150 \mathrm{~km}$.

Since the assessment of catalyst formulation and loading adapted to natural gas exhaust after-treatment had not been finalized, chassis-dynamometer bench tests (see Sect. 1.1.6) were carried out with a gasoline exhaust line.

\subsubsection{Engine Control}

Such a complex project has required a solid support from the point of view of engine control, throughout all its phases. As shown in Figure 3, the engine control development cycle at IFP can cover each phase of the project, from engine studies to vehicle demonstrator.

Thanks to this tool-chain, it is possible to design, test and validate the engine control system in a co-simulation
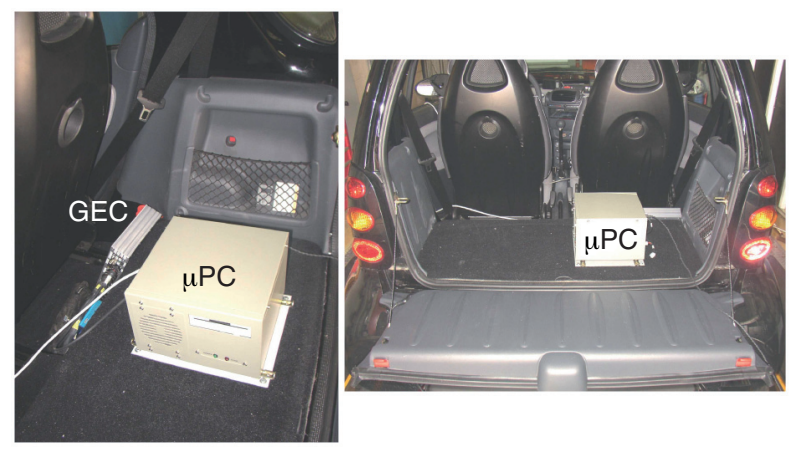

Figure 4

On-board electronics for engine control. 


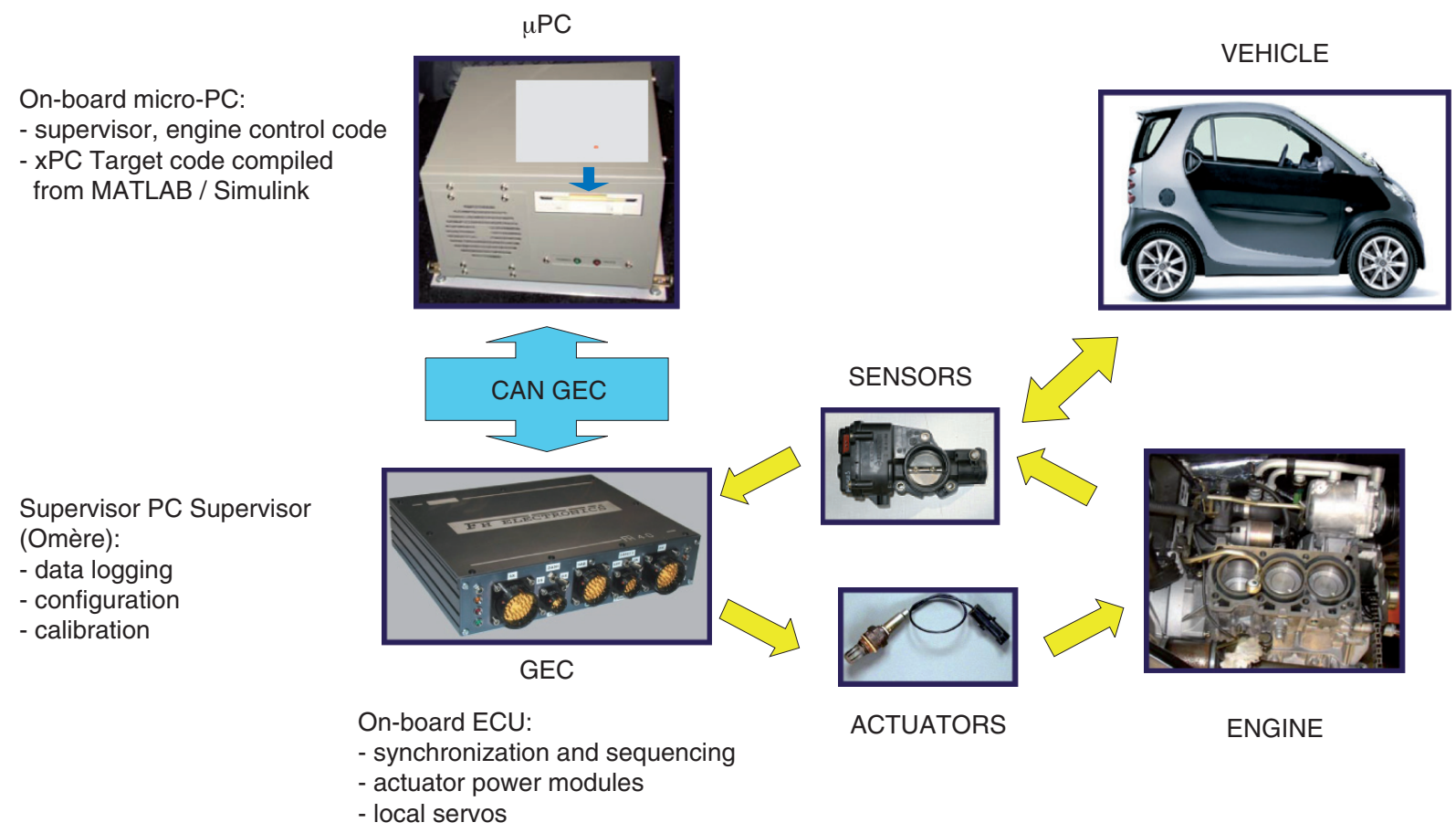

Figure 5

Structure of the on-board control system.

framework, with a control model running under Simulink and a detailed engine and/or vehicle model running under AMESim, using IFP Engine and Drive libraries [2].

As to implementation, a xPCTarget-based rapid prototyping system has been used both for the engine test bench and the vehicle. Engine bench tests were performed with our in-house electronic management system, ACEBox. The on-board system (Fig. 4) of the demonstrator is based on the GEC system developed by FH Electronics, and has the structure shown in Figure 5.

\subsubsection{Main Results of the First Smart Project}

Figure 6 compares break mean effective pressure versus engine speed at full load conditions, for natural gas and gasoline settings. From 2700 rpm to maximum engine speed, the turbocharger is able to compensate the volumetric efficiency drop, noticeable when using gaseous fuel. The maximum outputpower is not affected. At lower engine speed, maximum torque is obtained at $300 \mathrm{rpm}$ higher than for gasoline. This penalty does not affect significantly the vehicle behavior, but can still be felt by driver used to the brio of the gasoline version.

Looking at thermal efficiency, the natural gas curve stands out from the gasoline one with a favorable gap whatever the engine speed. From $2500 \mathrm{rpm}$, thermal efficiency obtained with natural gas is $25 \%$ higher than for gasoline, leading to a reduction of $\mathrm{CO}_{2}$ emissions close to $35 \%$, combining effects of compression ratio, settings and $\mathrm{H} / \mathrm{C}$ ratio. This good result is all the more advantageous that the swept volume is reduced (downsizing) and consequently, that high load is in demand.

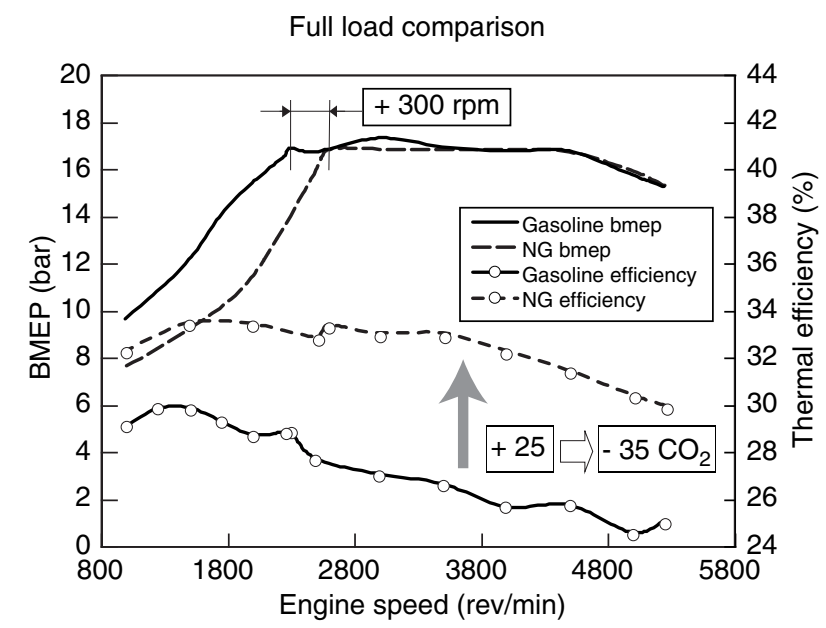

Figure 6

BMEP and thermal efficiency at full load (gasoline and natural gas). 


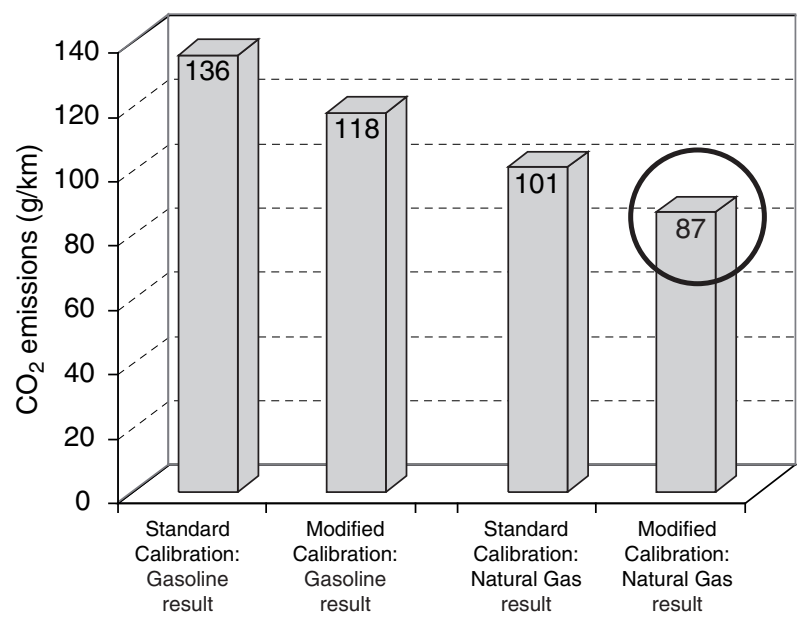

Figure 7

Smart results after recalibration of the chassis-dynamometer bench.

As to results on chassis-dynamometer bench, $\mathrm{CO}_{2}$ emissions on NEDC cycle were lower than $100 \mathrm{~g} / \mathrm{km}$ (Table 2), which corresponds to a total reduction of $27 \%, 23 \%$ due to natural gas and $4 \%$ to engine optimization. Concerning the other pollutants, results are comparable to gasoline ones.

TABLE 2

Smart results on NEDC with gasoline exhaust line (mean values over the last week of tests)

\begin{tabular}{l|c|c|c|c}
\hline & $\begin{array}{c}\mathrm{CO} \\
\mathrm{g} / \mathrm{km}\end{array}$ & $\begin{array}{c}\mathrm{HC} \\
\mathrm{g} / \mathrm{km}\end{array}$ & $\begin{array}{c}\mathrm{NOx} \\
\mathrm{g} / \mathrm{km}\end{array}$ & $\begin{array}{c}\mathrm{CO}_{2} \\
\mathrm{~g} / \mathrm{km}\end{array}$ \\
\hline Euro IV - 2005 & 1.00 & 0.10 & 0.08 & \\
\hline Gasoline [IFP] & $\mathbf{0 . 3 0}$ & $\mathbf{0 . 0 9}$ & $\mathbf{0 . 0 4}$ & $\mathbf{1 3 6 . 4}$ \\
\hline Natural Gas [IFP] & $\mathbf{0 . 3 1}$ & $\mathbf{0 . 1 1}$ & $\mathbf{0 . 0 5}$ & $\mathbf{1 0 0 . 0}$ \\
\hline
\end{tabular}

Those chassis-dynamometer results shows that the gasoline Smart vehicle under test emitted much higher $\mathrm{CO}_{2}$ emissions than the official figure of $118 \mathrm{~g} / \mathrm{km}$, probably due to friction loss difference.

To be able to estimate the real potential of the natural gas Smart demonstrator, the calibration of the chassisdynamometer bench (drag curve) had been adjusted in order to measure the official emissions, $118 \mathrm{~g} / \mathrm{km}$ instead of 136 $\mathrm{g} / \mathrm{km}$. As seen in Figure 7, the natural gas Smart demonstrator potential is lower than $90 \mathrm{~g} \mathrm{CO}_{2} / \mathrm{km}$, more efficient than the Smart diesel version.

\subsection{The VEHGAN Project: a Hybrid Version of the Smart Demonstrator}

The VEHGAN project (as "VEhicule Hybride au GAz Naturel") is a partnership among IFP, Gaz de France and
Valeo, with funding from ADEME (Agence De l'Environnement et de la Maîtrise de l'Énergie).

As already mentioned, its focus is to develop a new Smart CNG prototype, equipped with a small auxiliary power source, a reversible starter-alternator system. In a wider perspective, this project is also an excellent opportunity to bring to fruition all the improvements suggested by our experience with the previous demonstrator.

Project goals are:

- $\mathrm{CO}_{2}$ emissions lower than $80 \mathrm{~g} / \mathrm{km}$ (compared to the $87 \mathrm{~g} / \mathrm{km}$ of the first project);

- $\mathrm{CO}, \mathrm{HC}$ and NOx emissions (at least) complying with the EURO IV standard;

- better driveability at low engine speed.

\subsubsection{Improvement of Gas Adaptation}

Concerning the engine, the main undertaken action has been the increase of its swept volume by $10 \%$, from $600 \mathrm{cc}$ to $660 \mathrm{cc}$. As shown by Figure 8, this has reduced the torque gap between natural gas and gasoline version at low speed.

In addition, optimization of exhaust after-treatment formulation is underway, in terms of light-off strategies and catalyst formulation able to overcome the high stability of methane.

\subsubsection{The Starter-Alternator Reversible System}

The core of Valeo Starter-Alternator Reversible System (StARS) technology are belt-driven starter-alternators, whose basic functions are automated "Stop-Start", battery and engine load management. The Stop-Start function is used to turns the engine off automatically when the vehicle comes to

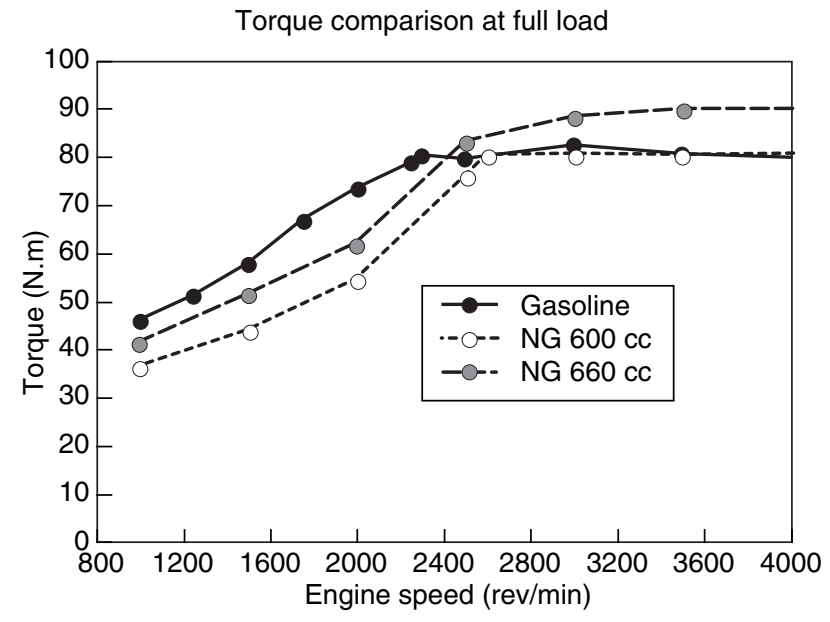

Figure 8

Torque increase at low speed obtained through increase of the swept volume. 


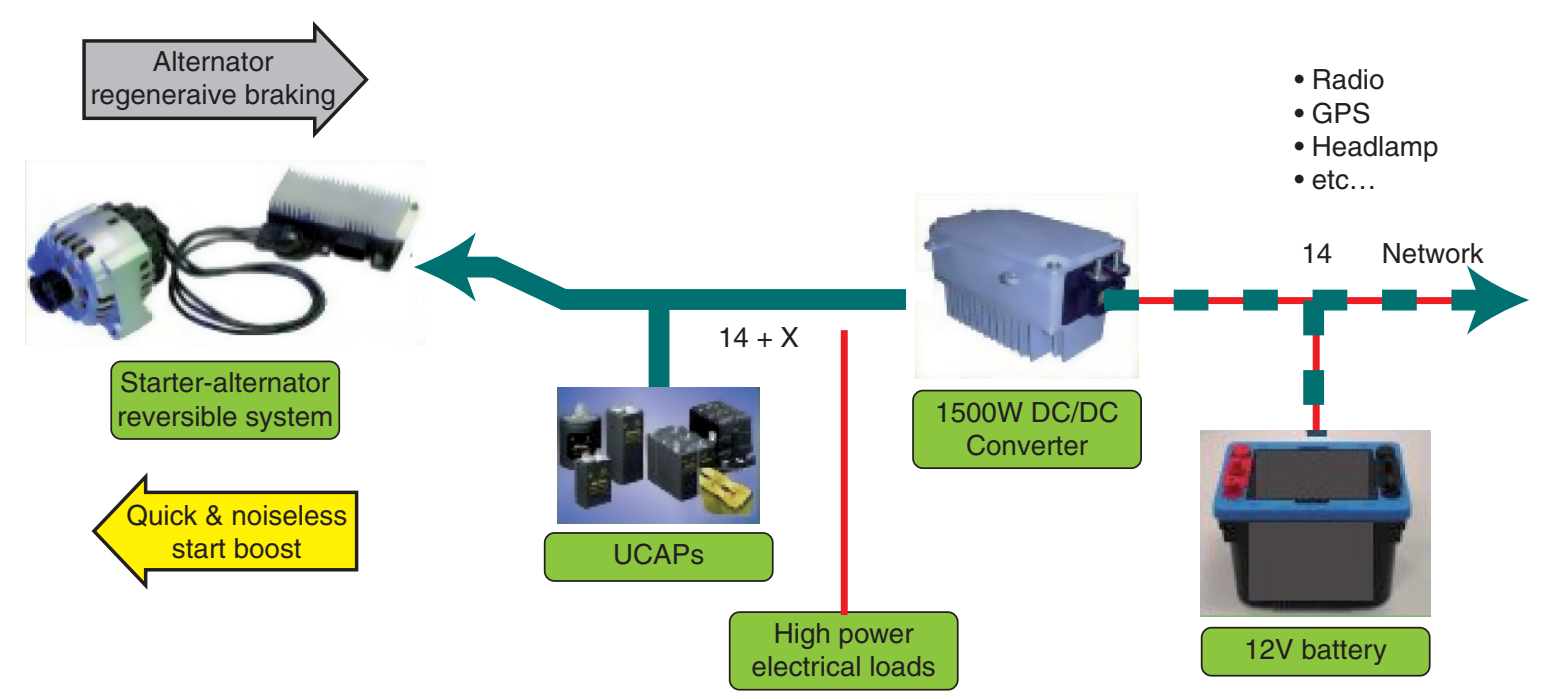

Figure 9

Valeo Starter Alternator Reversible System (StARS) for the demonstrator vehicle.

a standstill (red lights, temporary halts, traffic jams, etc.) and to restart the engine instantly and silently as soon as the driver releases the brake pedal or accelerates. Switching from inverter mode to rectifier mode, the reversible starter-alternator generates the electricity required for the vehicle.

Through a series of additional components, the performances and functions of the basic system can be extended to set up hybrid configurations of increasing complexity:

- micro-hybrid, providing only electrical power, but no mechanical power to the transmission;

- mild-hybrid, which can provide small mechanical power but not independently from the engine;

- full-hybrid, which implements a standard parallel hybrid configuration with the motor and the engine independently providing mechanical power to the same drive shaft.

The configuration chosen for our demonstrator vehicle, shown in Figure 9, is based on ultra-capacitors placed in a floating voltage network (from 14 to $24 \mathrm{~V}$ ). Since ultracapacitors have a much higher specific power than batteries, but a lower specific energy, they are typically used as power storage systems, for power assist during acceleration ("boost" mode) or hill climbing. Integrated in a low voltage network, they can also be used as an energy buffer capable of high power recuperation, coming for instance from the recovery of braking energy.

To sum up, the mild-hybrid configuration chosen for VEHGAN provides the following functions:

- "Stop-Start";

- regenerative braking with up to $4 \mathrm{~kW}$ of generated electrical power;
- power assist, of up to $3 \mathrm{~kW}$, during a limited time depending on the ultra-capacitor voltage.

Electrical power assist can be profitably used for torque "boost", improving the driveability at low speed, as shown in Figure 10.

More generally, even though this system does not have the flexibility of a full parallel hybrid configuration, the electrical assistance can be used to have the engine work on higher efficiency operating points.

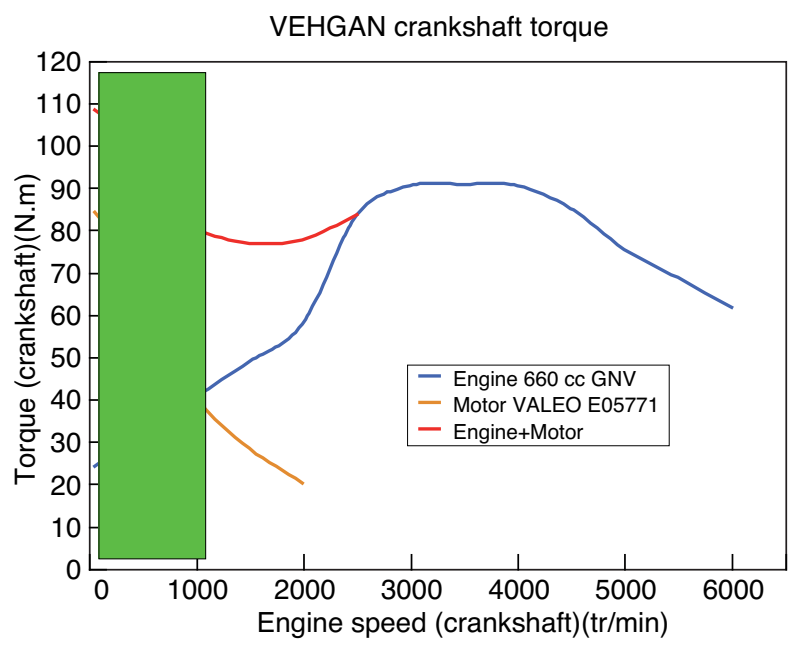

Figure 10

Torque increase at low speed using $3 \mathrm{~kW}$ electrical assistance. 


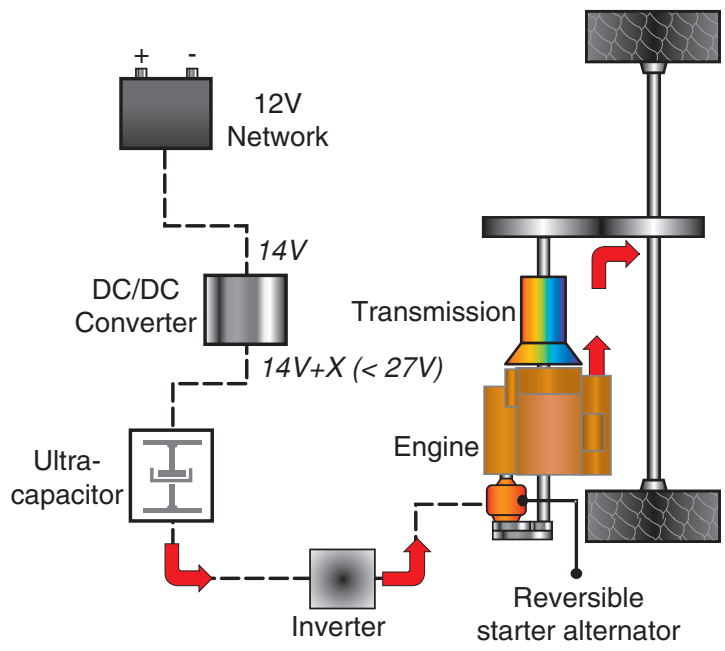

Figure 11

Power flow for boost or start mode.

\subsubsection{Automatic Manual Transmission Control}

To take full advantage of the mild-hybrid configuration the transmission of power to wheels (see Fig. 11) should be tightly controlled. This not only requires controlling a new power source, but also mastering the automatic manual transmission (AMT) control system.
This is why we decided to by-pass the AMT control of the production vehicle, and to design a new one to be integrated in our engine control structure.

\section{DRIVELINE MODELING AND CONTROL}

\subsection{The Smart Driveline}

The standard version of Smart ForTwo is equipped with an automated manual transmission (AMT) system, represented in Figure 12. With this transmission system, the driver does not directly act on the clutch (no clutch pedal) nor on the gearbox. The driver expresses his/her will to shift gears or to start the vehicle through the gearshift lever and the accelerator pedal, but those actions are actually carried out by the AMT control system through clutch-by-wire and shift-bywire systems. By pushing a button on the gearshift lever, the driver can also opt for an automatic shift transmission (AST) mode. The appropriate gear ratio is automatically selected, thus implementing the functions of truly automatic transmission (AT) systems, with less comfort, though. Indeed, in AT systems, torque transmission to wheel is never interrupted, thanks to the use of more complex (and expensive) transmission elements like torque converters, planetary gears or continuously variable transmissions (CVTs). On the other hand, AMT systems only require automation and minor modifications of two standard driveline components, the complexity being moved to control electronics and software. This is particularly true when considering the Smart vehicle, where clutch and gearbox are actuated through simple DC motors.

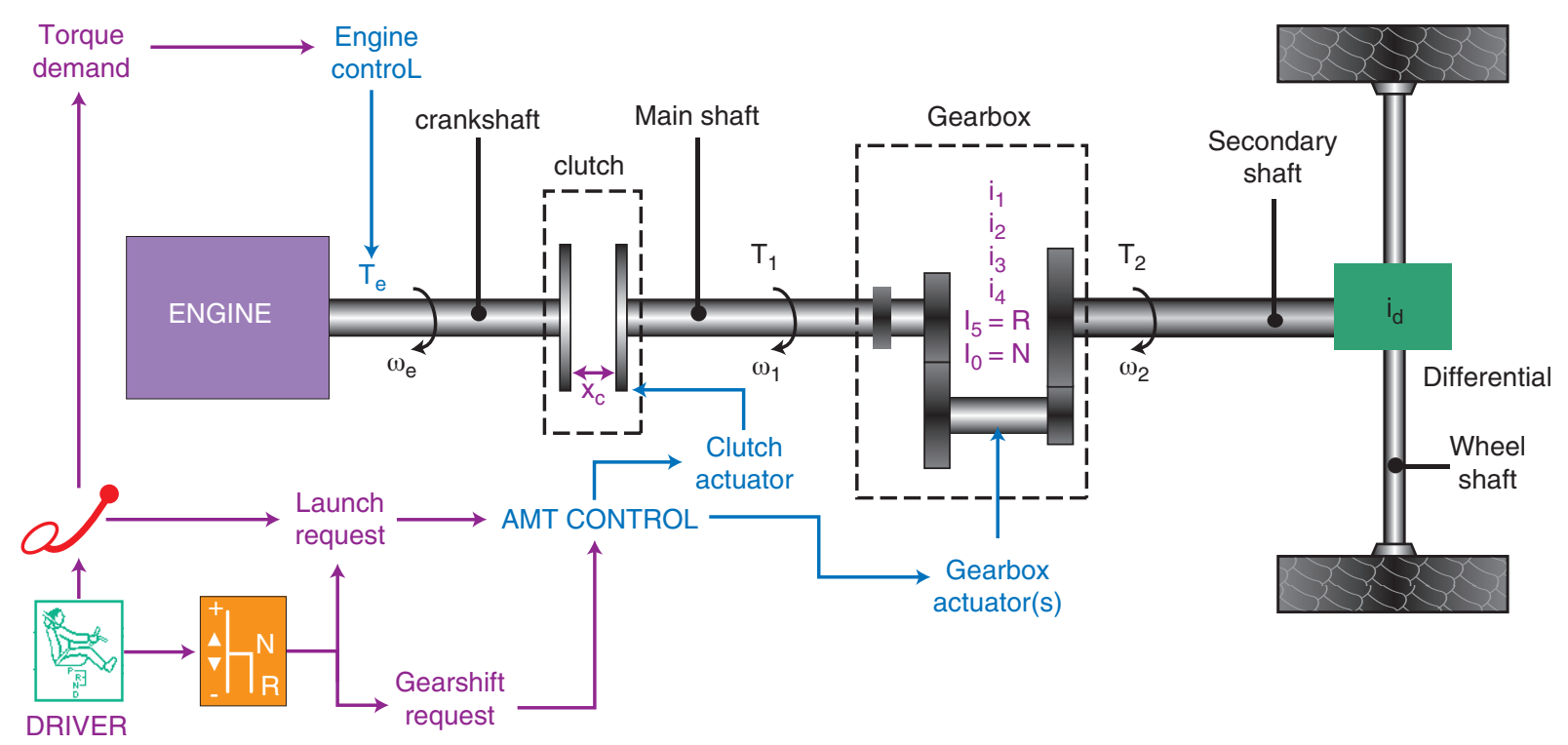

Figure 12

Automated manual transmission (AMT) system. 


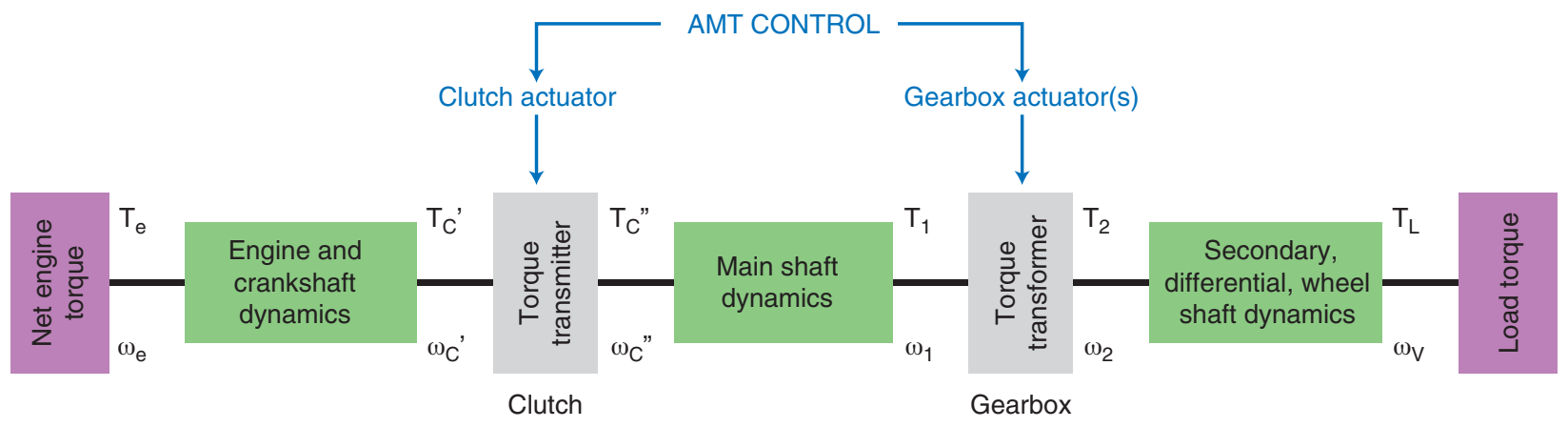

Figure 13

Conceptual driveline scheme for AMT.

\subsection{Driveline Modeling for AMT}

A conceptual sketch of the driveline for AMT systems is represented in Figure 13. The clutch smoothly connects the flywheel to the main shaft, rotating at different speeds, thus allowing the transmission of (net) engine torque to the wheels. The role of the gearbox is to extend secondary shaft (and wheel shaft) speed range from the limited range of engine speeds to the larger range of possible vehicle speeds, transforming speed and torque through gear ratios.

As underlined in [4-6], an automated manual transmission with (dry) clutch can be assimilated to a hybrid system, that is a system mixing discrete-event dynamics and continuoustime dynamics.

The discrete-event part is associated to the different states the clutch and the gearbox can be in. The clutch can be disengaged (or fully open), with zero torque transmitted to the main shaft, engaged (or fully closed), with the engine torque completely transmitted to the main shaft, or in an intermediate state, with the clutch disk slipping before complete engagement or disengagement. As to the gearbox, different states correspond to different gear ratios (including neutral). A further state corresponds to the synchronization phase before the engagement of a new gear ratio.
The continuous-time part takes in rotational dynamics of the different shafts. A sensible approach consists in lumping driveline parts that rotate together when the clutch and the gearbox interrupt torque transmission. With respect to Figure 13, we can distinguish, from engine to wheels: engine and flywheel dynamics, main shaft dynamics including the parts of clutch and gearbox rotating with it, and the dynamics of the rotating parts comprised between the gearbox parts on the secondary (or transmission) shaft side and the wheels. The next issue is how to characterize each dynamics in terms of moment of inertia, torsion, damping. Let us focus on the most important phase for vehicle start-up and gear shifting, that is the clutch slipping phase during engagement, when the friction between clutch disk and flywheel allows engine torque transmission to the main shaft then to the transmission shaft. For this phase, a typical modeling choice is to consider the main shaft rigid (as proposed in [5] and restated in [9]):

$$
\left\{\begin{aligned}
J_{e} \dot{\omega}_{e} & =T_{e}-T_{c} \\
J_{m}^{\prime} \dot{\omega}_{g} & =T_{c}-k_{v}^{\prime} \theta-\beta_{v}^{\prime}\left(\omega_{g}-\omega_{v}\right) \\
J_{v}^{\prime} \dot{\omega}_{v} & =k_{v}^{\prime} \theta-\beta_{v}^{\prime}\left(\omega_{g}-\omega_{v}\right)-T_{L} \\
\dot{\theta} & =\omega_{g}-\omega_{v}
\end{aligned}\right.
$$

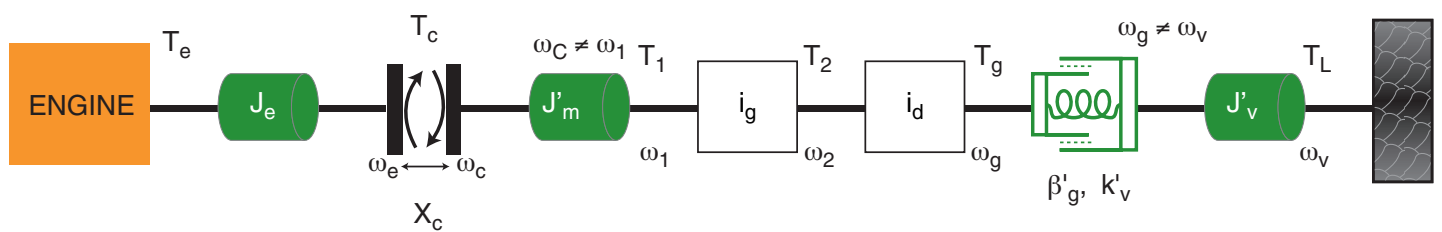

Figure 14

Modeling of the clutch slipping phase. 
where $T_{e}$ is the net engine torque, $T_{c}$ is the torque transmitted by the clutch, $T_{L}$ is the load torque; $\omega_{e}, \omega_{g}$ and $\omega_{v}$ are, respectively, the engine, gearbox and vehicle speed; $J_{e}, J_{g}^{\prime}$ and $J_{v}$, the engine, (equivalent) main shaft and (equivalent) vehicle inertias; $\theta$ is the transmission shaft torsion; $k_{v}^{\prime}$ and $\beta_{v}^{\prime}$ the (equivalent) transmission shaft stiffness and damping coefficients (Fig. 14).

It should be pointed out that for our vehicle, since the engine is mounted on the rear wheel shaft, only minor torsional behavior is present in the (equivalent) transmission shaft, so it could be considered rigid as well (at least in the clutch slipping phase). However, in our simulation model in AMESim, as shown in Figure 15, we preferred to include visco-elastic behavior in both the main shaft and the transmission shaft, in order to check robustness of control laws.

\subsection{Modeling and Control of Transmission Actuators}

\subsubsection{Clutch}

In our vehicle, the mechanism permitting to press the clutch disk against the flywheel (and to release it) is actuated through a simple electrical motor. Therefore, contrary to other more complex clutch actuators (hydraulic ones, for instance), a simple PD controllers suffices to get a good setpoint tracking, with no overshoot and a settling time of $\approx 100 \mathrm{~ms}$ for small changes and of $\approx 200 \mathrm{~ms}$ for steps from fully engaged to fully disengaged position (or vice versa). This controller as well as other local control loops (gearbox, pedals), is implemented in the on-board power ECU (GEC).

Incidentally, since the clutch disk thickness may vary, the actuator position corresponding to a fully engaged clutch

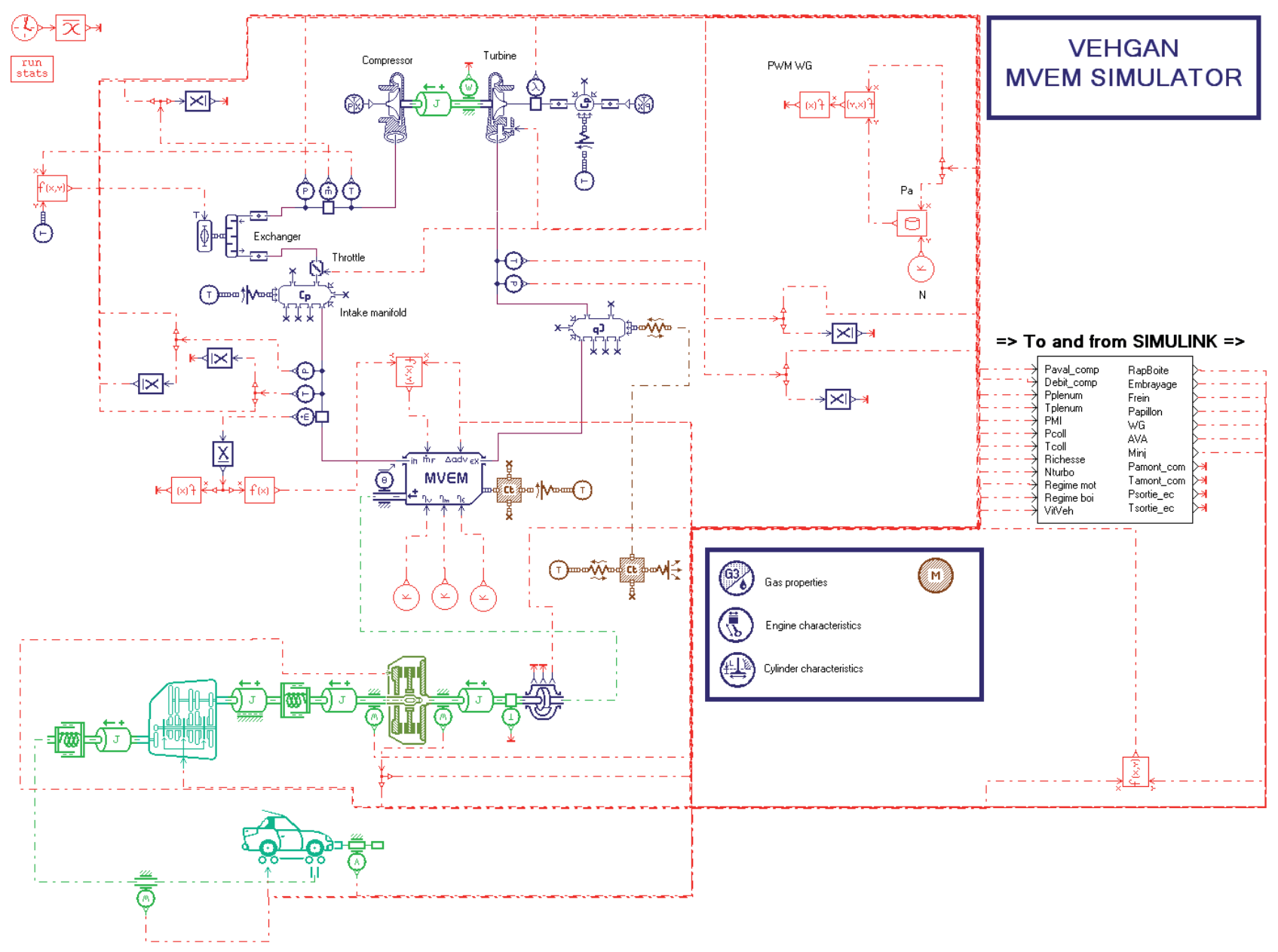

Figure 15

AMESim simulation model. 
may also vary, thus requiring an actuator calibration phase when the control software starts. The finite state machine (FSM) for calibration is implemented in the upper layer of the engine control system, the Simulink-generated xPCTarget code running on the on-board micro-PC.

To effectively use the clutch for implementing vehicle launch or gear shifting strategies, the clutch behavior as a torque transmitter must be described.

As a matter of fact, transmitted torque depends on many other factors, as shown by the following equation:

$$
T_{c}=k\left(T^{\circ}, \omega_{s l}\right) F_{n}\left(x_{c}\right) \operatorname{sign}\left(\omega_{s l}\right)
$$

where $x_{c}$ is the clutch actuator position, $F_{n}\left(x_{c}\right)$ is the normal force applied to the disk, $\omega_{s l}$ is the difference between engine speed and clutch speed (slipping speed), and $k\left(T^{\circ}, \omega_{\text {sl }}\right)$ is the dynamic friction coefficient, function of temperature $T^{\circ}$ and of slipping speed $\omega_{s l}$, times a constant factor depending on clutch geometry. On a different time scale, the effects of clutch wear should also be included in this expression.

Since complete identification of those dependencies is very difficult, we can assume, as suggested in [5], that the torque transmitted by the clutch is only related to the clutch actuator position $x_{c}$, and try to estimate a static non-linear map $T_{e}\left(x_{c}\right)$ using the following equation:

$$
J_{e} \dot{\omega}_{e}=\hat{T}_{e}-T_{c}\left(x_{c}\right)
$$

where $\hat{T}_{e}$ is an estimation of engine torque (since a measure of the actual engine torque is seldom available on production vehicles). Notice that, contrary to [5], we do not use directly the engine torque set-point for clutch torque estimation, but instead an estimate of engine torque taking into account engine torque dynamics.

We can recognize here a simple problem of unknown input estimation, generally described by:

$$
\dot{z}=y+x
$$

where $z$ and $y$ are measured signals and $z$ is the unknown (unmeasured) signal to be estimated. An overview of several unknown input estimation algorithms and their properties, with some applications to engine control, is provided in [7].

Though the authors of [5] advocate the use of a dirty derivative estimation:

$$
\widehat{x}=\frac{s z}{\tau s+1}-y=\frac{z}{\tau}-\frac{z}{\tau(\tau s+1)}-y,
$$

in our implementation we found that the results obtained with this solution are too sensitive to noise.

We opted for a high-gain observer instead:

$$
\hat{x}=\gamma z-\varepsilon
$$

defined through two auxiliary variables $\mathrm{v}, \varepsilon$, and the equations:

$$
\left\{\begin{array}{l}
v=\gamma z-\varepsilon-x \\
\dot{\varepsilon}=-\gamma \varepsilon+\gamma y+\gamma^{2} z
\end{array},\right.
$$

and converging to $x$ for $\gamma$ sufficiently high. See again [7] for a more detailed explanation.

This method gave us smoother results and, incidentally, the observer gain proved to be a more flexible parameter than the dirty-derivative filter time constant.

Figure 16 shows some preliminary results of this approach, with a cloud of estimated values and the piecewise linear approximation (a look-up table) which is presently used for clutch control. With no transmission test bench at our disposal, we could only validate the position of the torque transmitting point. Estimation errors in the rest of the characteristic, mainly due to imperfect engine torque knowledge, are to be compensated by closed-loop control.

In order to thoroughly validate our approach, two parallel actions are underway:

- estimate $T_{c}$ via the main shaft motion equation:

$$
J_{m}^{\prime} \dot{\omega}_{g}=T_{c}-k_{v}^{\prime} \theta-\beta_{v}^{\prime}\left(\omega_{g}-\omega_{v}\right)
$$

and an estimation of load torque which would be available, for instance, during chassis-dynamometer bench tests;

- measure $T_{c}$ indirectly via a torque sensor placed on the transmission shaft.

Up to now, we have only used the estimation approach off-line. From our tests, it appears that a form of on-line

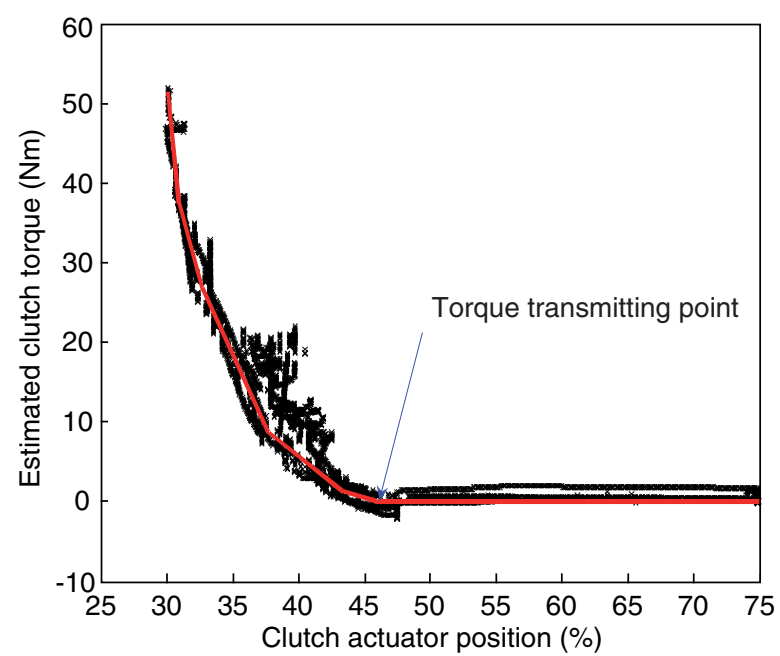

Figure 16

Transmitted clutch torque characteristic: estimated values and piece-wise linear approximation. 
estimation, at least of the torque transmitting point, would be advisable to cope with temperature related changes.

For simulation purposes, a Powertrain library block was used in AMESim, including a reset integrator model for friction and simplified internal damper and a static nonlinearity on the control input. Actuator dynamics were modeled as well.

\subsubsection{Gearbox}

Smart gearbox is also controlled through a DC motor, but with a more complex mechanism. The DC motor rotates a barrel connected to three forks, each of them actuating a synchronizer. As a result, gears are engaged sequentially as the DC motor rotates. Notice that, as shown in Figure 17, to shift from second to third gear and from fifth to sixth, the gearbox must pass through a "false" neutral position.

Again, PD control was used for the DC motor but with a different strategy. In fact, mechanical clearances between the DC motor and the barrel make it difficult to determine an absolute (or relative, between 0 and $100 \%$ ) set-point value corresponding to the requested gear. So we adopted an incremental set-point strategy, starting from the knowledge of the currently engaged gear. This approach has required a complex supervisor FSM in the upper level control software, but it is totally transparent for the AMT control strategies,
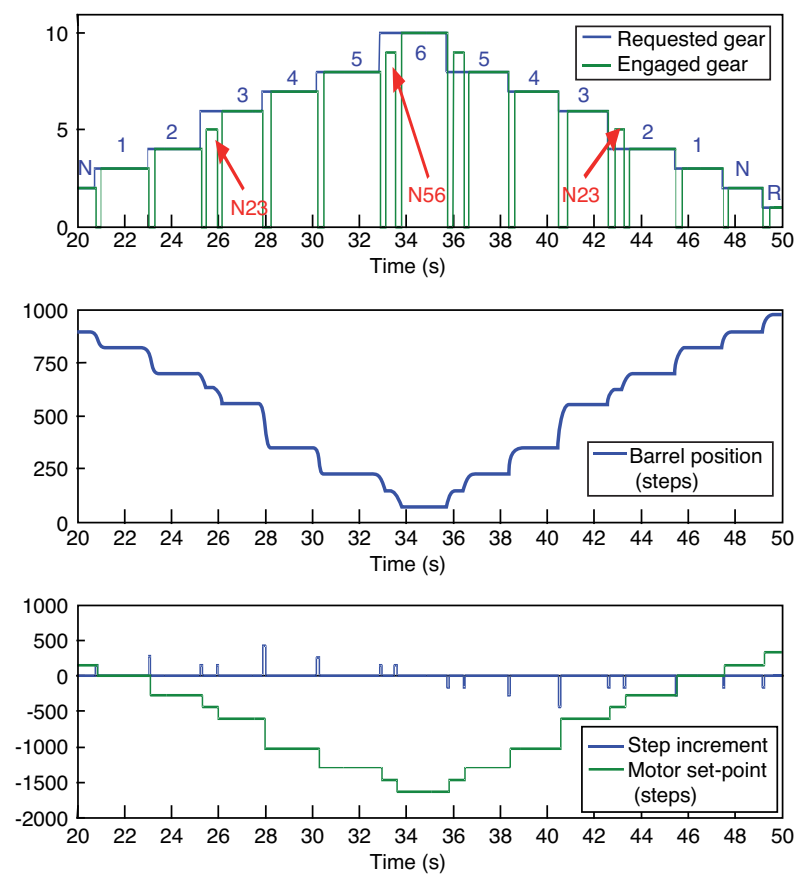

Figure 17

Gearbox actuator control behavior (with clutch open). The barrel locks in ten different positions, each corresponding to a gear or a neutral position. which just need to deal with "high-level" set-points (requested gear numbers).

As to performances, gear engagement times are similar to those of the original gearbox control, that is, not very fast (between 350 and $400 \mathrm{~ms}$, and twice that when a "false" neutral position must be crossed).

Concerning simulation, we did not try to model synchronization dynamics, since they are quite fast compared to gear engagement time and car longitudinal dynamics. Thus, a simple block from the IFP Drive library was used in AMESim for the gearbox, instead of the more complex ones of the Powertrain library. Nonetheless, we included a detailed model of the closed-loop gearbox actuator behavior and dynamics.

\subsection{AMT Control Strategies}

Clutch and gearbox servos provide the AMT control system with two commands: requested gear (ratio) and clutch position (or clutch torque) set-point. These manipulated variables are to be used by the AMT control system, in collaboration with the engine control system, to execute complex task as vehicle start-up and gear shifting. In production cars, these functions are mostly implemented in open-loop via look-up tables and usually require a good deal of calibration to achieve satisfying performances. Only in recent times, closed-loop strategies have started to draw the attention of car manufacturers and suppliers.

Potential benefits of the use of closed-loop control to implement AMT functions are:

- improved robustness with respect to uncertain or varying components and parameters in the system (i.e. clutch torque characteristics);

- more accurate control of factors influencing the quality of the implemented functions, such as clutch engagement time and driveline oscillations;

- reduced calibration time, provided that the behavior of the closed-loop system can be related to few high-level tuning parameters.

Furthermore, closed-loop strategies do not need additional measurements than those required by conventional AMT control: clutch actuator position, and main shaft and/or secondary shaft speed. On the other hand, a higher investment in control design and modeling is to be expected.

From the discussion on driveline modeling, it should be clear that the hybrid nature of AMT operation should be taken into account when designing control strategies. Possible solutions range from explicit hybrid control formulation as in [8] to the hierarchical framework of [6], where different controllers are activated by a finite state machine with states corresponding to each AMT operating phase. The latter approach has inspired most of the AMT control strategies tested in simulation and those currently implemented on 


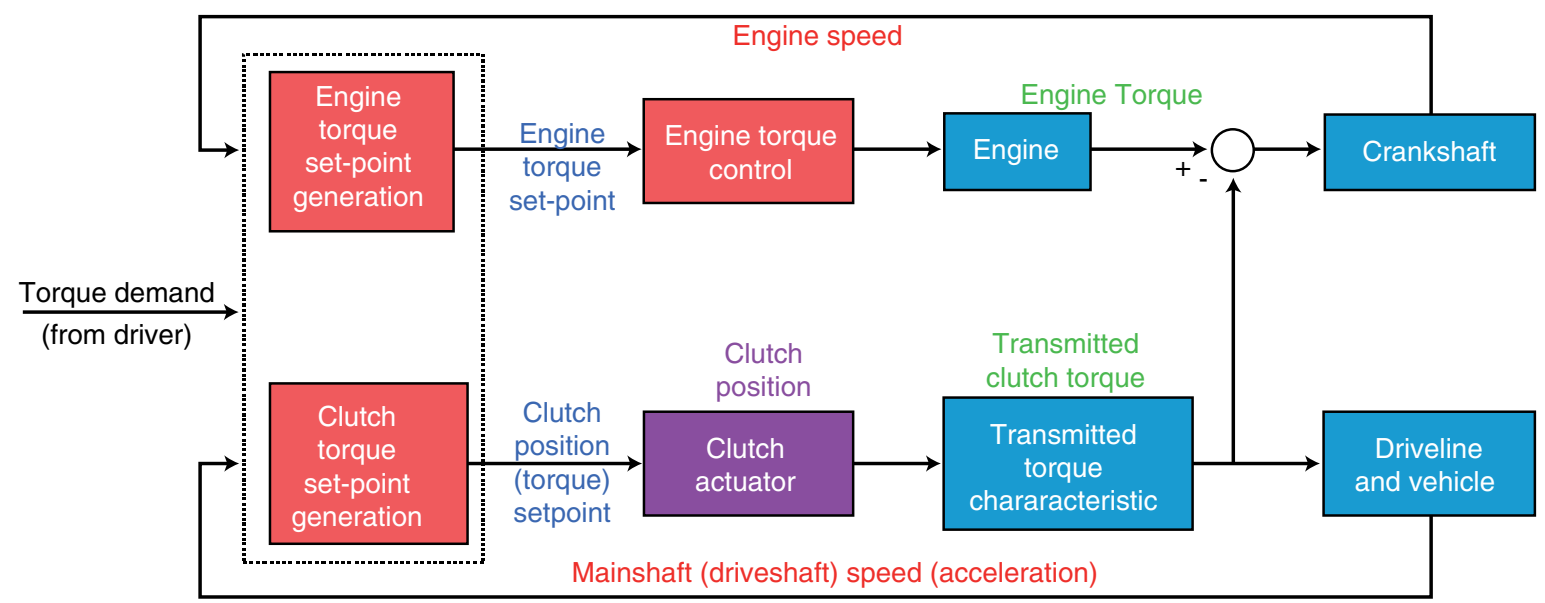

Figure 18

Control scheme for the clutch slipping phase.

the vehicle, because it fits very well the hierarchical and modular structure of our control software.

Concerning the structure of the sub-controllers for the different phases, most of them are really simple and include many open-loop parts, the exception being the controller for the clutch slipping closing phase when engine torque is transmitted to the wheels through the clutch.

As shown in Figure 18, during this phase the two manipulated variables that are at our disposal are the engine torque (set-point) and the clutch torque or position (set-point). With those command inputs, we can in principle control engine speed on one side, and one of the available measured outputs (speeds, accelerations) of the driveline, or a combination of the two (e.g. clutch slipping speed).

Depending on the available measurements, on the actuator bandwidth and authority, different control structures can be devised: a two-input two-output (TITO) controller, two decentralized controllers, or a single closed-loop controller.

Notice that since there is a physical coupling between engine and driveline dynamics during this phase, there is potentially a lot to gain from a close cooperation (or from the integration) of the engine control and the transmission control modules.

\section{AMT Control for Vehicle Start-up}

Assuming the clutch already open (disengaged), the implementation of a vehicle start-up strategy requires closing the clutch to progressively transmit engine torque to the driveline, until main shaft speed reaches engine speed and clutch locks up. During this process certain specifications must be met:

- $\omega_{e}^{\min } \leq \omega_{e}(t) \leq \omega_{e}^{\max }, \forall t$, that is engine stall must be avoided (no-kill condition) as well as engine over revolution;
- $\dot{\omega}_{s l}\left(\bar{t}^{-}\right)=\dot{\omega}_{e}\left(\bar{t}^{-}\right)-\dot{\omega}_{c}\left(\bar{t}^{-}\right)$, that is, the difference between engine and main shaft acceleration at lock-up must be minimized to avoid oscillations (no-lurch condition);

- $E_{d}=\int_{0}^{\bar{t}} \omega_{s l}(t) T_{c}(t) d t$, the energy spent during engagement, must be minimized.

It is possible to fulfil these specifications by incorporating them into optimal control problems (as in [3, 8, 9]), even though the resulting control law is usually quite cumbersome to implement. Otherwise, conventional structures can be used, as the decentralized PID controllers on engine speed and slipping speed suggested in [5], provided that "sensible" trajectories are chosen for the controlled variables.

After having tested in simulation some of the strategies proposed in literature, for a first vehicle implementation, we settled for a very simple one, adapted from the approach described in [10]. The underlying idea is to let engine torque control respond in open-loop to driver request (which is the standard engine control behavior, when the accelerator pedal is pressed) and have the clutch position take care of the engine speed, via a PI controller (Fig. 19). When the engine speed $\omega_{e}$ exceeds a set-point $\omega_{e}^{S P}$ (higher than idle speed), the clutch starts closing, thus reducing $\omega_{e}$.

If controller tracking dynamics is fast enough, after a transient we will have:

$$
J_{e} \dot{\omega}_{e} \cong 0 \Rightarrow T_{e}-T_{c} \cong 0 \Rightarrow T_{c} \cong T_{e} \cong T_{e}^{s p},
$$

that is, the torque transmitted to the driveline during start-up will be approximately equal to the torque requested by the driver. This gives us a way to act on vehicle acceleration during vehicle start-up, in the same way as engine control normally responds to acceleration pedal requests with the 


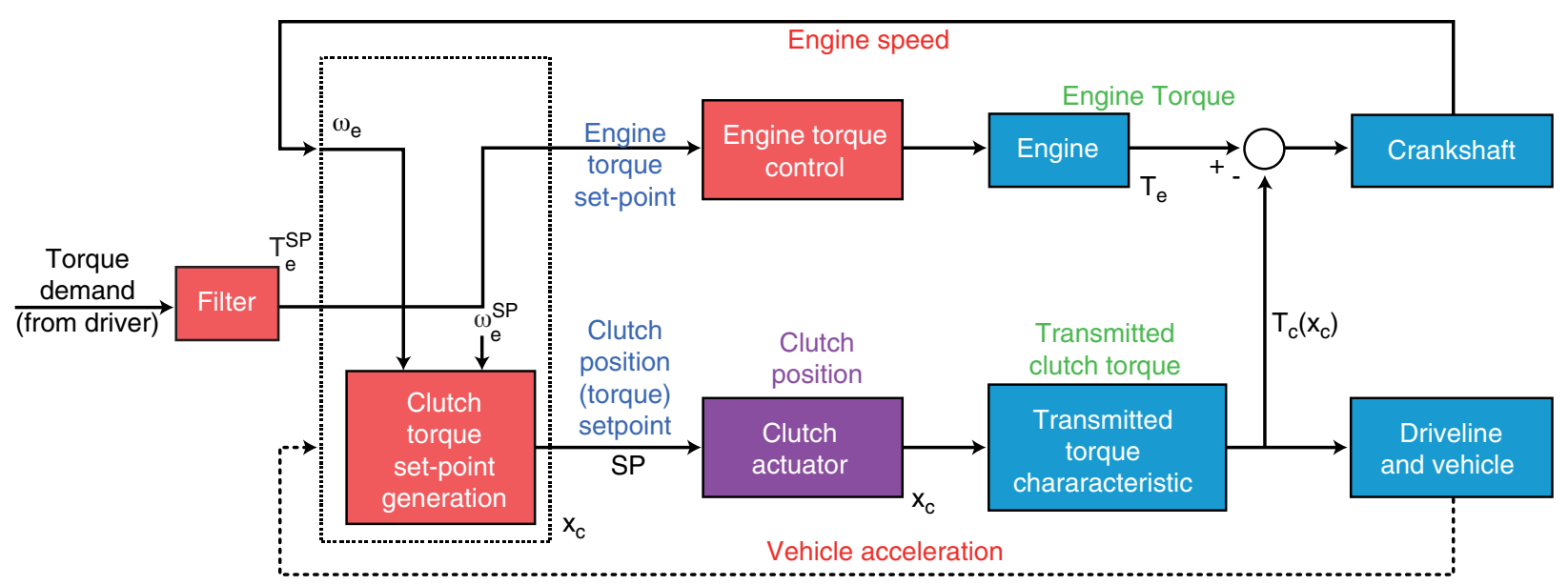

Figure 19

Controlling engine speed with clutch position during vehicle start-up.

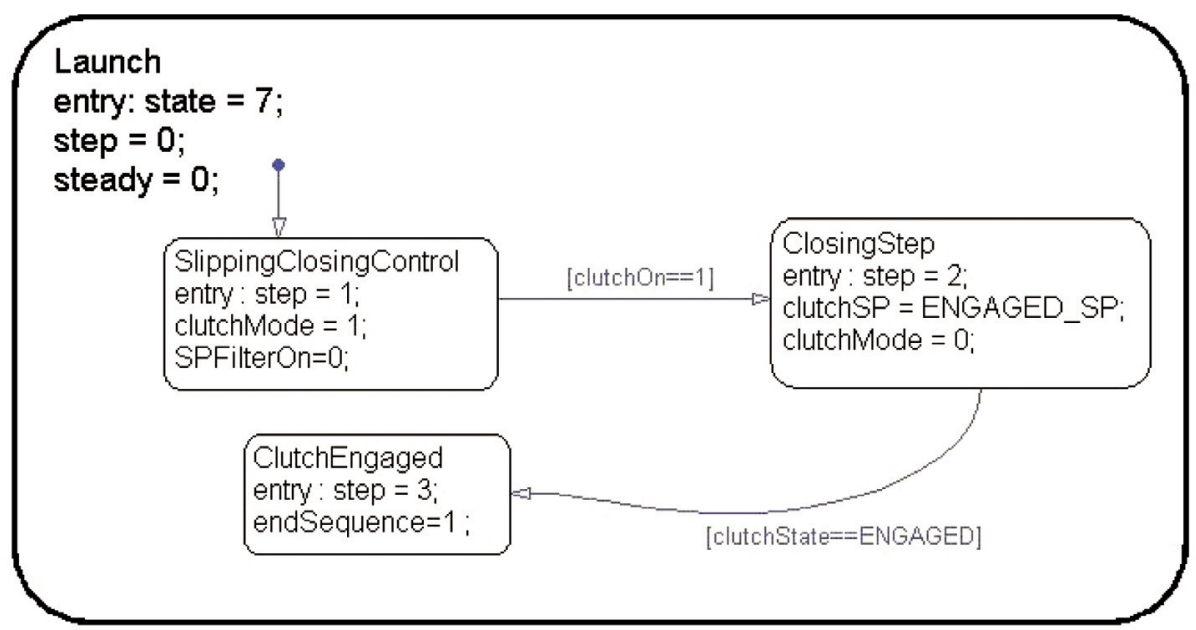

Figure 20

Stateflow supervisor for vehicle launch.

Figure 21

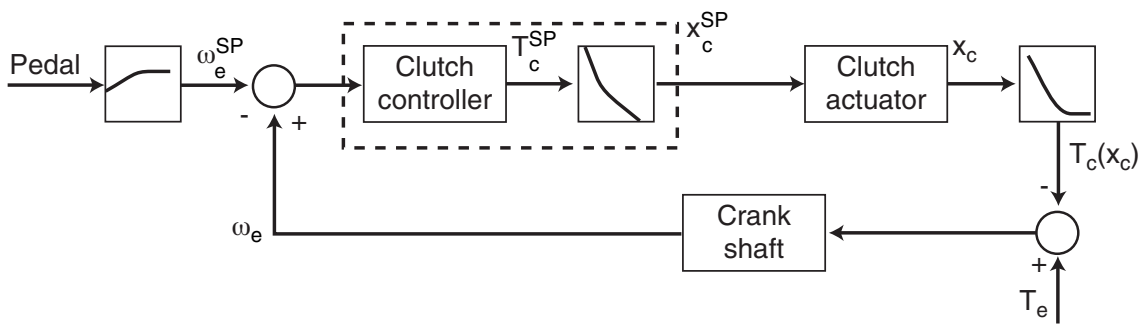

Slipping closing controller for vehicle launch. 
clutch fully engaged. Notice that when the driver releases the pedal, engine speed drops below the set-point, and the clutch automatically reopens.

Though this is basically the same strategy described in [10], it should be pointed out that several improvements are necessary to make it viable. First of all, a hybrid supervisor (Fig. 20) is needed to fully close the clutch after lock-up, otherwise the clutch would indefinitely stay in the lock-up position. Then, the non-linear clutch torque characteristic should be taken into account in the controller (that is, inverted), as shown in Figure 21. This also implies prepositioning the clutch actuator at the torque transmitting point, instead to let it start from the fully open position.

This strategy proved very easy to implement and to calibrate (parameters are PI gains and a small look-up table). Figure 22 shows some typical experimental results. Oscillations at engagement are small, and the resulting driver feeling is quite good.

\subsection{AMT Control for Gear Shifting}

As with manual transmission, gear shifting in AMT with dry clutch requires clutch opening before engagement of a new gear, and is concluded by a clutch closing phase. Meanwhile, the engine speed must be adapted to the new gear ratio.

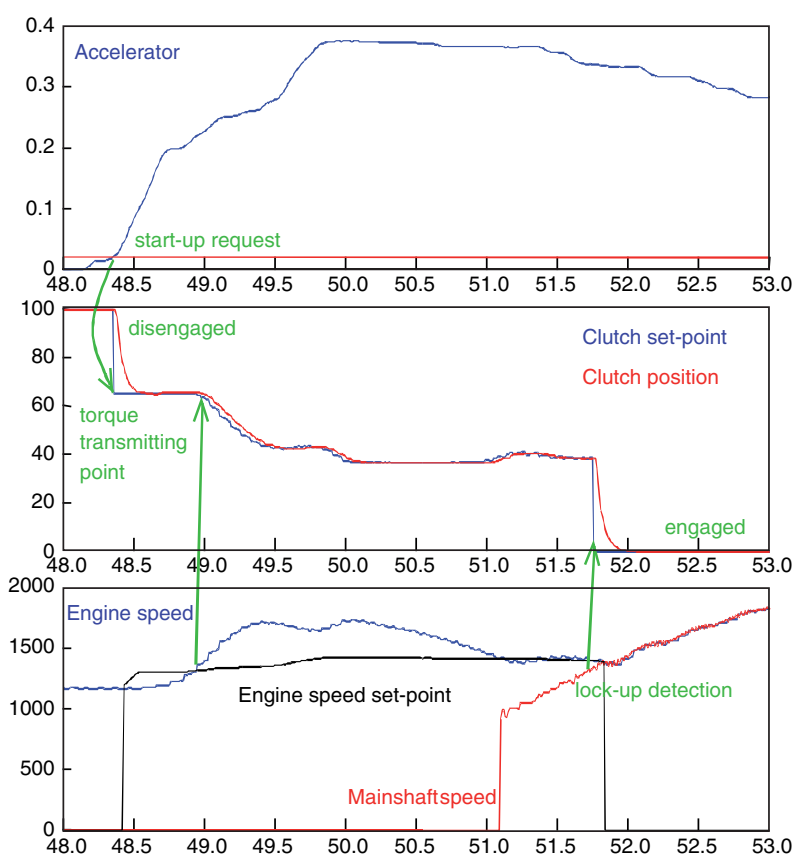

Figure 22

Experimental results with the proposed vehicle launch strategy.
Though much shorter than in vehicle start-up, the clutch slipping closing phase is critical again. However the overall quality of a gear shift depends on many different factors such as minimization of engine torque discontinuities or respect of driver's comfort and expectations. Taking into account these factors in terms of control specifications formulation is not trivial.

Once again, the hybrid framework proposed in $[5,6]$ proved an excellent starting point to set-up a viable AMT control strategy. Figure 23 shows a Stateflow supervisor for gear up-shift.

We can distinguish three main phases:

- clutch opening in open loop (with a ramp then a step reference);

- engaging of a new gear (synchronization);

- clutch closing in closed loop until clutch lock-up (including clutch pre-positioning at torque transmitting point).

Engine speed tracking is activated at the beginning of gearshift operations and deactivated at the end, with modifications of engine speed set-point at each intermediate state.

During the slipping closing phase, closed-loop control is thus performed within the general framework of Figure 18, using engine torque to control engine speed, and clutch position to control main shaft speed or clutch slipping speed. Setpoint generation for this structure is not straightforward, because engine speed must be brought close to main shaft speed at the end of the gearshift, giving a right interpretation of driver's will (via the accelerator pedal), while ensuring that the clutch will close completely.

The currently implemented control structure (shown in Fig. 24) takes the absolute value of the slipping speed to insure complete clutch closing even when engine speed drops below main shaft speed. As in [5, 6], a feed-forward controller is used to quicken engine speed response to engine torque. Notice that the starter alternator could be really useful in this phase, with its boost (for down-shifts) and braking (for up-shifts) capabilities.

Figure 25 shows some preliminary experimental results obtained with this strategy corresponding to a shift from 1 st to 2 nd gear. Further work is needed to improve speed tracking and reduce oscillations at lock-up. Results for three consecutive up-shifts are shown in Figure 26.

\subsection{Integrated Powertrain Control for AMT}

Integration of AMT control strategies within the torquebased structure of engine control software must be done carefully to manage the increased complexity, while preserving flexibility and ensuring readability.

One possibility consists in merging the standard engine control supervisor with finite state machines taking care of AMT strategies. In our opinion, this approach inevitably leads to a very complex code, hard to develop and to maintain. 


\section{Upshitt}

entry: state $=9$

step $=0$;

steady $=0$

userLpShift $=0$;

shifting $=1$;

GoToSlippingopening

entry: $T 0=t ; N=0=N \mathrm{Ne}$;

endSequence $=0$; step $=1$;

NeActualPos = NeO;

rpmTrackingSP $=$ NeO; No_new $=$ NeO;

clutchSP $=$ ENGAGED_SP;

clutchliode $=0$;

timeToLockup = timeToLockupupshift+delta_ti;

ppinTrackingon = 1 ;

cupling: step I IITe $=\mathrm{t}-\mathrm{TO}$;

exit:gr_old=GearRatio(userGear);

gr_new $=$ GearRatio $(\min (6$, userGear +1$))$;

NeActualPos = rmTrackingSP;

rpmTrackingSP $=$ Nwheel*gr_new+delta_NeSP;

No new =gr_new $w^{*}$ w wheel+delta_NeSP:

startRamp $=1$;

[icture

[(clutchNearlyon $=1)($ clutch $S P>=$ finalclutch $S P)]$

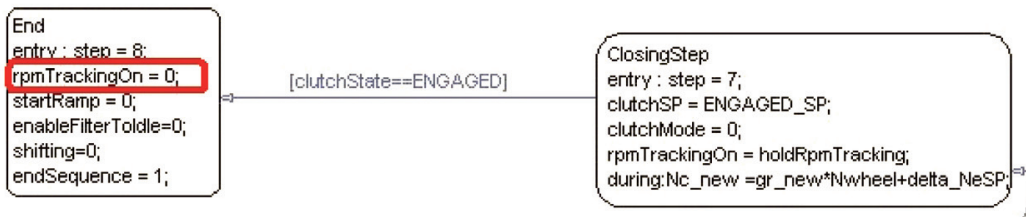

shifting $=0$

entry: step $=7$

$=$ ENGAGED SP:

during:Nc_new =gr_new $w^{*}$ wwheel+delta_NeSP;

$\Rightarrow$ entry: $\mathrm{TO}=\mathrm{t}$; step $=3$

entry: $\mathrm{To}=\mathrm{t}$; step $=2$;

finalClutch $\mathrm{SP}=$ =trqTransmit_sp+deltaTrqTransnit_sp;

clutch $\mathrm{PP}=\min (\mathrm{clutch} \mathrm{SP}+\ldots$

slippingopeningSlope ${ }^{*} \mathrm{Ts}$, finalClutchSP) :

during : stepTime $=\mathrm{t}-\mathrm{TO} ; \mathrm{Nc}$ _new $=\mathrm{gr} \_$new $\mathrm{Nw}^{*}$ weel+delta_NeSPi

entry: T0 $=t$ step $=4$, userGear $=$ min $(6$, userGear +1$)$

gr $=$ GearRatio(userGear);

requestedGear $=$ GearConversion(UserGear);

during: stepTime $=\mathrm{t}-\mathrm{TO}_{\mathrm{i}}$

Nc_new =gr_new*Nwheel+delta_NeSP;
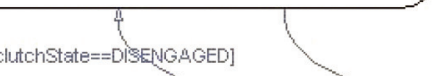
gearChangeok $=1$ clutchSP $=$ DISENGAGED_SP;

during : stepTime $=\mathrm{t}-\mathrm{TO}$;

Ne new =ar new* Wwheel+delta NeSP:

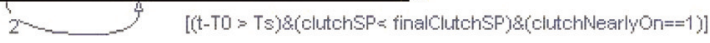

Figure 23

Stateflow supervisor for gear up-shift, with activation of slipping closing clutch control (red box) and of engine speed tracking (green box).

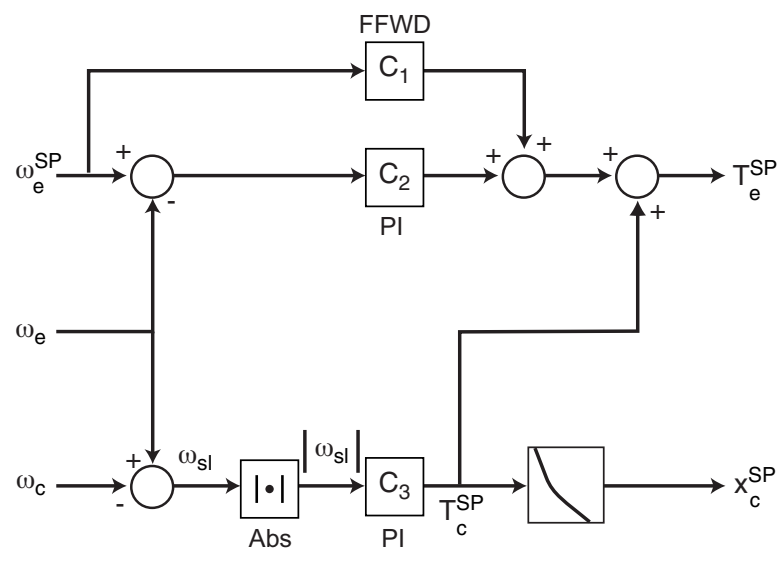

Figure 24

Slipping closing controller for gear-shifting.

This is why we opted for a decentralized structure, where powertrain states of a relatively simple supervisor at the vehicle manager level (see Fig. 27), are mapped into engine states and transmission states at a lower hierarchical level.

Powertrain states, such as stand-by, start-up, up-shift, down-shift, etc., are triggered by driver requests expressed
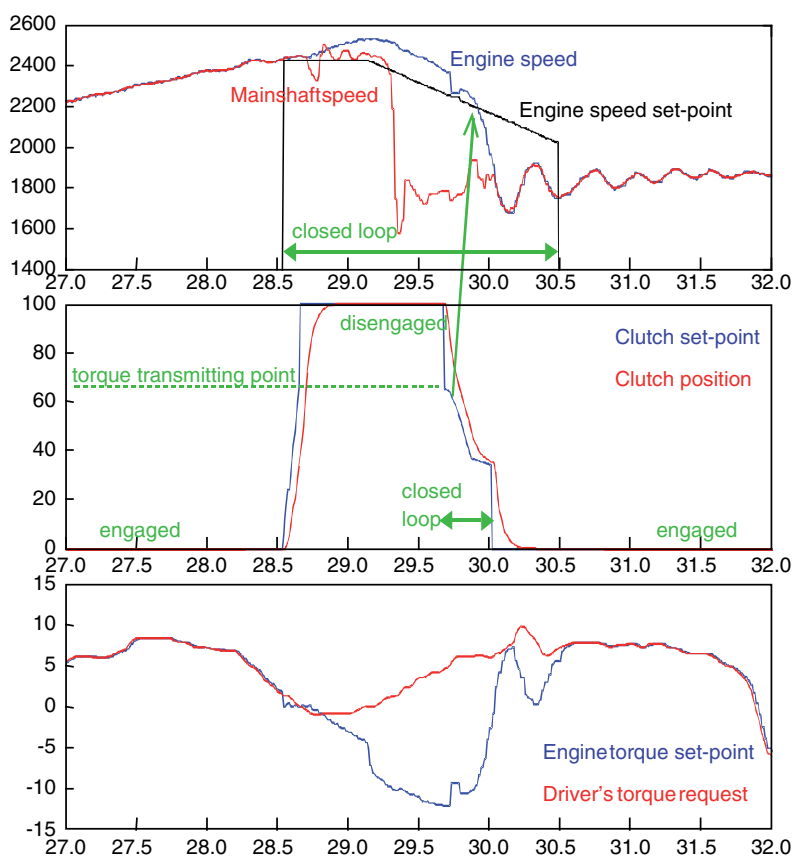

Figure 25

Experimental results for a gearshift from 1st gear to 2nd gear. 

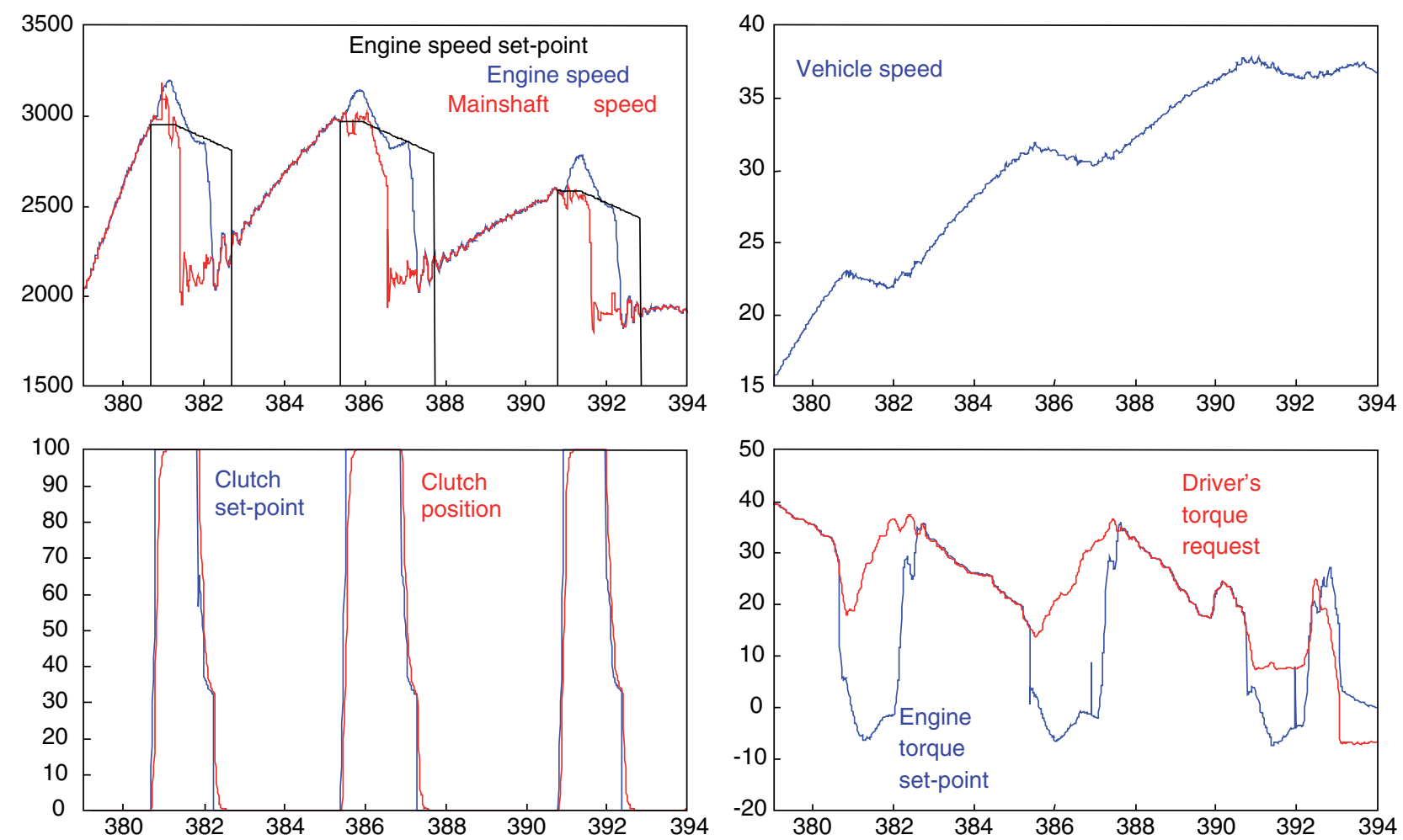

Figure 26

Experimental results for three consecutive up-shifts (from 1st gear to 4th gear).

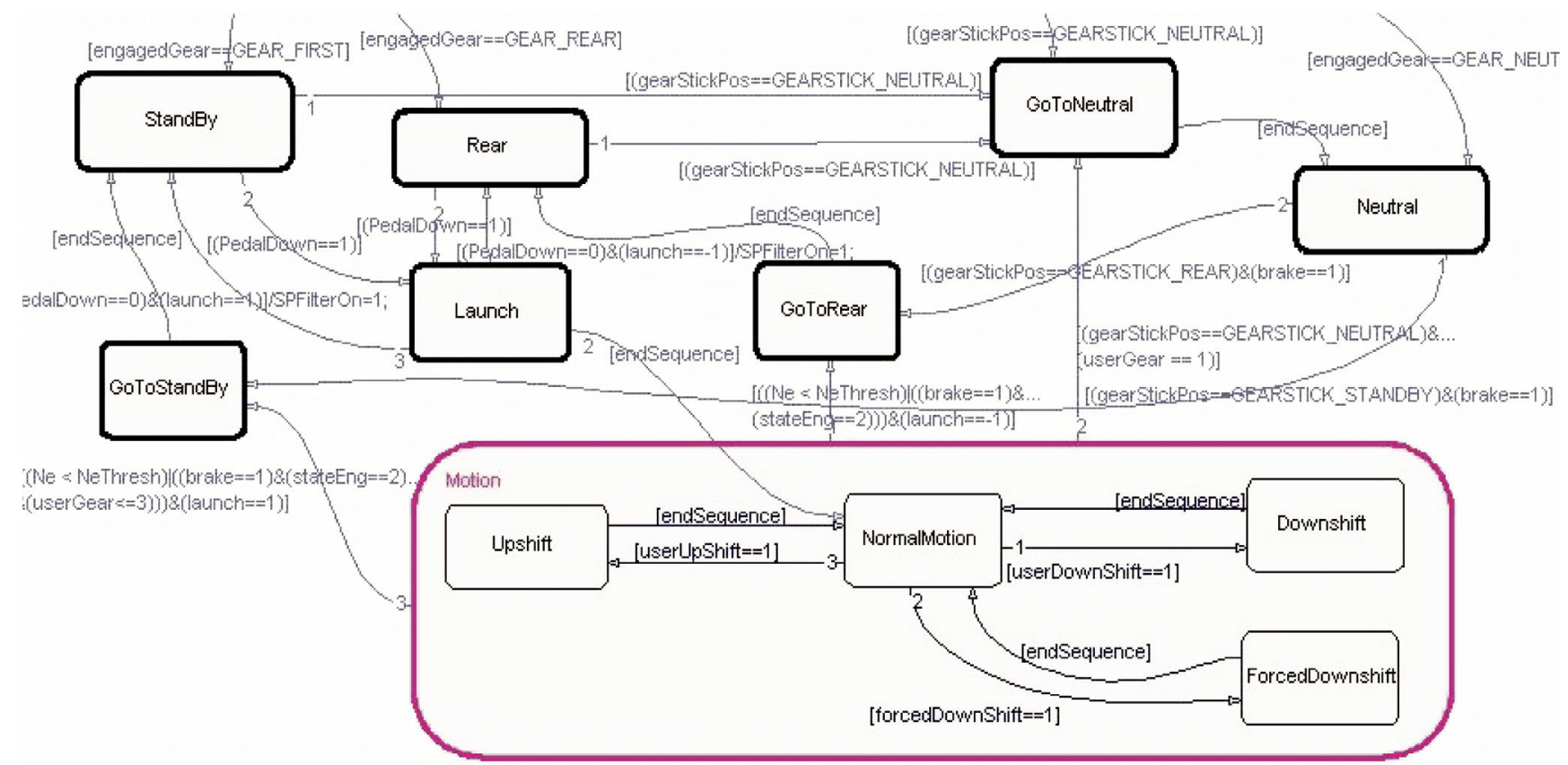

Figure 27

Powertrain manager (detail). 


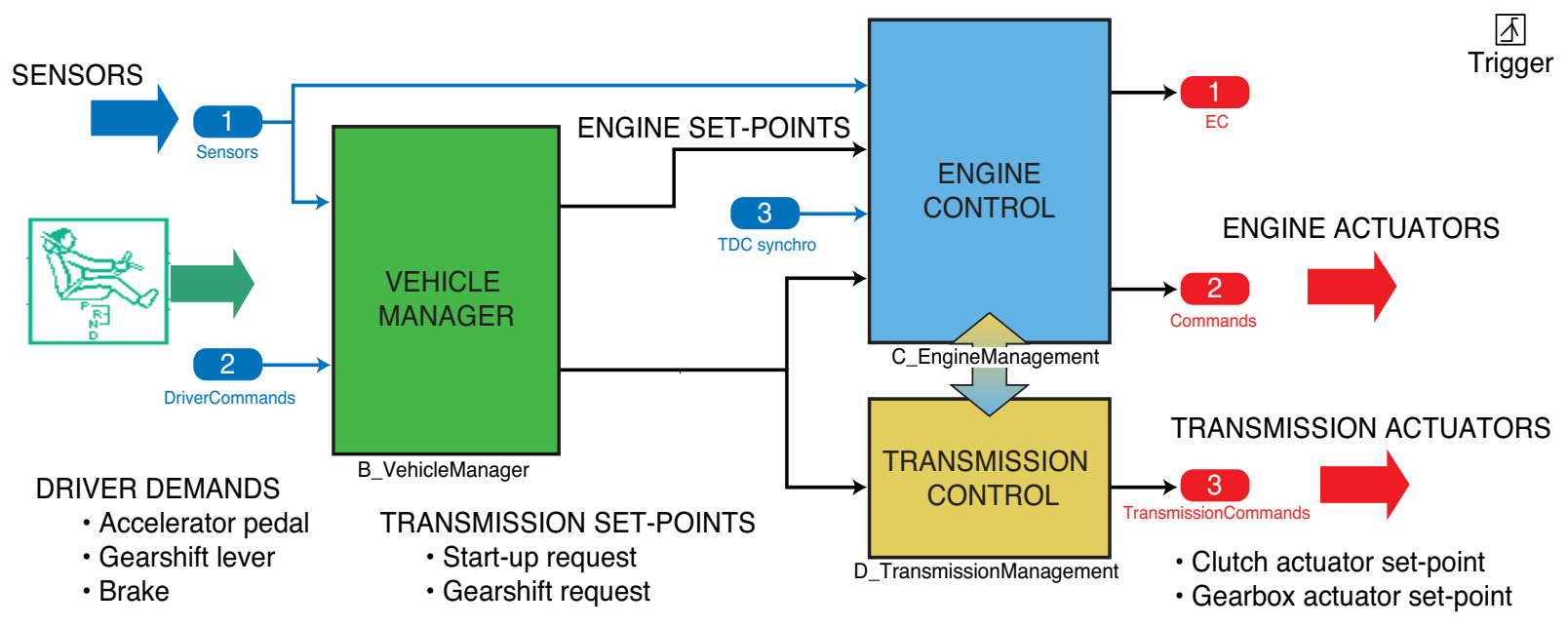

Figure 28

Software structure of integrated powertrain control for AMT.

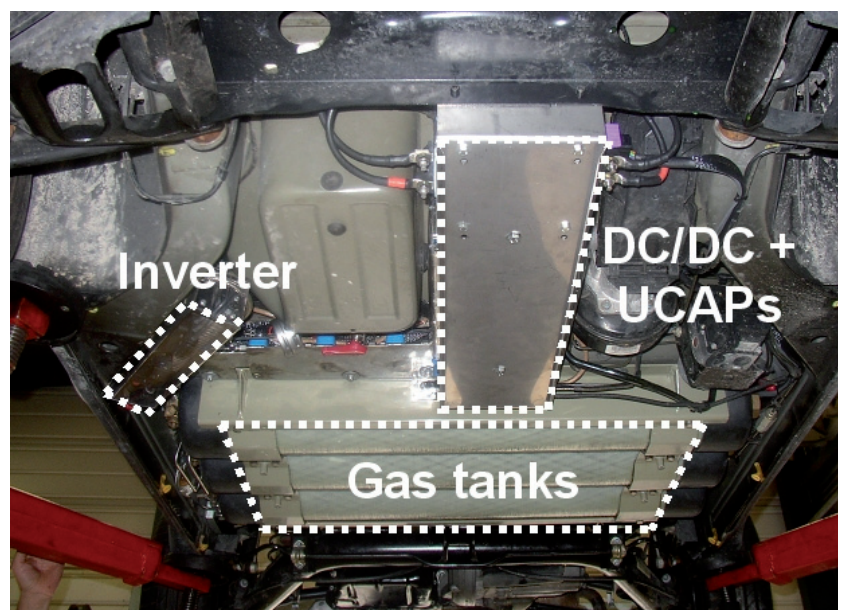

Figure 29

StARS under vehicle chassis.

through the accelerator pedal, the gearshift lever and the brake pedal. Engine states are the standard states (stop, idle, pedal mode, cut-off and so on) of the engine control manager, with an additional speed-tracking state, activated during gear shifting. Transmission (control) states correspond to gearbox operations, such as gear engagement request, and clutch control states (open loop, slipping closing control).

\section{WORK IN PROGRESS}

At the time of writing, the final versions of engine and exhaust line system have already been installed on the vehicle, together with starter-alternator system. The latter has been fitted into empty spaces under the chassis (Fig. 29), with no change to vehicle dimensions. Vehicle weight has increased by only about $10 \mathrm{~kg}$, the ultra-capacitors being very light compared to batteries.

The high-level functions of the StARS system (start, boost, regenerator and alternator modes) have been validated and can be controlled through the structure shown in Figure 30. At the moment, boost and regenerator modes are not connected to any supervisory strategy whatsoever, and can only be operated manually.

In parallel with the validation of the different parts of the integrated powertrain control structure, the main subject of research will be the development of appropriate real-time strategies for on-board power management to be integrated with the vehicle manager.

We will also try and design an automatic shift (AST) layer, performing gearshifts that would optimize for efficiency the operating point of the hybrid engine-motor system, while maintaining driver comfort.

\section{CONCLUSION}

This paper has presented an overview of the work done so far to develop an integrated powertrain control system for an urban vehicle with a downsized turbo-charged $\mathrm{CNG}$ engine, equipped with a starter-alternator with power assist and energy recuperation capabilities.

As a prior condition for the tight control of power flows from the hybrid power sources to the wheels, a complete automated manual transmission (AMT) control system has been designed and implemented.

We devised a lightweight integrated powertrain control structure, flexible enough to carry out advanced AMT control strategies, which have been implemented and tested on the 


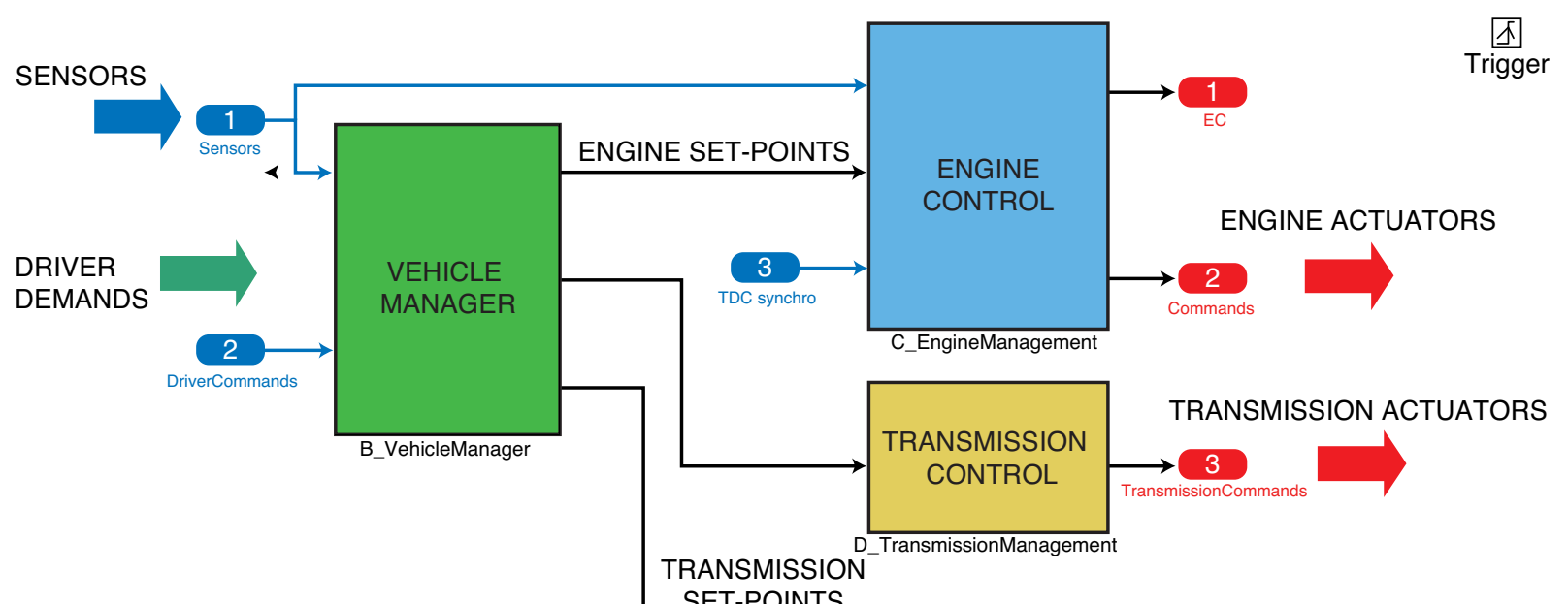

SET-POINTS

Figure 30

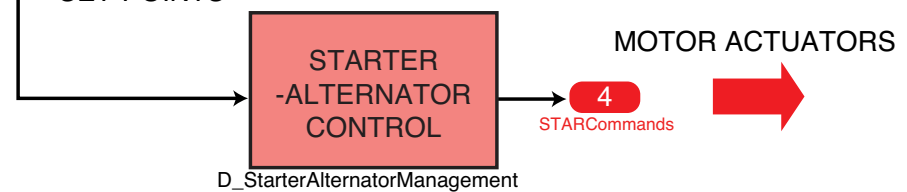

Integrated powertrain control for the mild-hybrid demonstrator.

demonstrator vehicle. Further work is needed to improve the performances of automated gear shifting.

The last part of this project will focus on the reversible starter-alternator system and the development of on-board energy management strategies.

\section{ACKNOWLEDGEMENTS}

IFP wishes to thank its partners Gaz de France and Valeo for their cooperation, and ADEME for its financial support and for its interest and confidence in this project.

\section{REFERENCES}

1 Tilagone R., Venturi S., Monnier G. (2005) Natural Gas: An Environmentally Friendly Fuel for Urban Vehicles: The SMART Demonstrator Approach, SAE Transactions, J. Fuels Lubricants 114, 4, 1066-1073.

2 Albrecht A., Grondin O., Le Berr F., Le Solliec G. (2006) Towards a stronger simulation support for engine control design: a methodological point of view, E-COSM - Rencontres Scientifiques de l'Institut français du pétrole, 2-4 October 2006.

3 Glielmo L., Vasca F. (2000) Optimal Control of Dry Clutch Engagement, Transmission and Driveline Symposium 2000 (SP-1522), SAE 2000 World Congress, Detroit, Michigan, 6-9 March 2000.
4 Garofalo F., Glielmo L., Iannelli L., Vasca F. (2001) Smooth engagement for automotive dry clutch, Proceedings of the 40th IEEE Conference on Decision and Control, 4-7 Dec. 2001.

5 Glielmo L., Iannelli L., Vacca V., Vasca F. (2004) Speed control for automated manual transmission with dry clutch, Proc. 43rd IEEE Conference on Decision and Control, Atlantis, Paradise Island, Bahamas, 14-17 Dec. 2004, WeA09.6, pp. 1709-1714.

6 Glielmo L., Iannelli L., Vacca V., Vasca F. (2006) Gearshift Control for Automated Manual Transmissions, IEEE/ASME T. Mechatronics 11, 1, 17-26.

7 Stotsky A., Kolmanovsky I. (2002) Application of input estimation techniques to charge estimation and control in automotive engines, Control Eng. Pract. 10, 1371-1383.

8 Bemporad A., Borrelli F., Glielmo L., Vasca F. (2001) Hybrid control of dry clutch engagement, European Control Conference, Porto, Portugal, Oct. 2001.

9 Dolcini P., Canudas de Wit C., Bechart H. (2005) Improved Optimal Control of Dry Clutch Engagement, Proc. 16th IFAC World Congress, session 7.1, Prague, Czech Republic, 4-8 July 2005.

10 Zanasi R., Visconti A., Sandoni G., Morselli R. (2001) Dynamic modeling and control of a car transmission system, Proceedings 2001 IEEE/ASME International Conference on Advanced Intelligent Mechatronics, Como, Italy, 8-12 July 2001, Vol. 1, pp. 416-421.

Final manuscript received in August 2007 or distributed for profit or commercial advantage and that copies bear this notice and the full citation on the first page. Copyrights for components of this work owned by others than IFP must be honored. Abstracting with credit is permitted. To copy otherwise, to republish, to post on servers, or to redistribute to lists, requires prior specific permission and/or a fee: Request permission from Documentation, Institut français du pétrole, fax. +33147527078 , or revueogst@ifp.fr. 